Panahi, H., Kobchenko, M., Meakin, P., Dysthe, D. K., \& Renard, F. (2019). Fluid expulsion and microfracturing during the pyrolysis of an organic rich shale. Fuel, 235, 1-16.

\title{
Fluid expulsion and microfracturing during the pyrolysis of an organic rich
} shale

\author{
Hamed Panahi ${ }^{1}$, Maya Kobchenko ${ }^{1}$, Paul Meakin ${ }^{1,3}$, Dag Kristian Dysthe ${ }^{1}$, and François Renard ${ }^{1,2}$ \\ ${ }^{1}$ Departments of Geosciences and Physics, Physics of Geological Processes, University of Oslo, \\ Norway \\ ${ }^{2}$ University Grenoble Alpes, ISTerre, CS 40700, F-38058, Grenoble cedex 9, France \\ ${ }^{3}$ Departmnt of Physics, Temple University, Philadelphia, Pennsylvania
}

* Corresponding author: hamedp@mail.uio.no

ABSTRACT

During progressive burial, low permeability organic-rich shale rocks evolve chemically and physically as the temperature and stress increase and organic matter matures. The transformation of organic matter into hydrocarbon, followed by its expulsion into secondary migration pathways along which it is conveyed into reservoirs rocks, is a coupled process that involves chemical reactions, changes in volume and stress leading to the nucleation and growth of microfractures, the opening and closing of these microfractures, and fluid transport through them. Primary migration was studied using an experimental setup that was designed to measure changes in fluid pressure, which are correlated with organic matter maturation and hydrocarbon expulsion. The setup consisted of a pressurized autoclave which was externally heated. Shale samples were confined, under an initially low confining pressure and an applied differential stress $(0.18 \mathrm{MPa})$, and heated to temperatures of $210-320^{\circ} \mathrm{C}$. Changes in temperature, static pressure (pressure measured using a linear response transducer) and dynamic fluid pressures (measured using a piezoelectric differential transducer) in the autoclave chamber were monitored and recorded during each experiment. In the higher part of the temperature range, fluid produced by kerogen 
maturation and the concomitant formation of microfractures increased volumetric expansion of the shale. Power spectral densities of the fluid pressure signals were calculated and a conceptual model is proposed to explain the dynamics of fluid expulsions. While a power law distribution of frequencies of pressure burst amplitudes was identified, the frequencies of time intervals between successive expulsion events (waiting times) decrease monotonically with increasing waiting time. Co-generation of gas and liquid hydrocarbon was evidenced. Several samples were imaged after kerogen maturation using X-ray microtomography, and the data confirm the existence of a percolating network of microfracture that controls the primary migration of hydrocarbons.

\section{KEYWORDS}

shale; primary migration; pressure time series; X-ray tomography; microfracture formation; flow in dynamic fractures

\section{INTRODUCTION}

Identifying the processes that control the flow of hydrocarbons in tight rocks is important in understanding primary migration from source rocks into secondary migration pathways and how to increase the recovery of hydrocarbons from tight rocks formations [1]. Continuous burial of sedimentary rocks that are rich in organic content results in evolution of these materials and formation of organic fluids (oil and gas) and highly aromatic insoluble organic solids (matured kerogen and pyro-bitumen). As the temperature and pressure increase during progressive burial a complex mixture of fluids including hydrocarbons, carbon dioxide and water is produced. At first, the hydrocarbon produced by thermal decomposition (catagenesis) of the kerogen consists primarily of oil, but as the temperature and pressure continue to increase, the average molecular mass of the hydrocarbon produced from the kerogen decreases and eventually only natural gas is produced. In addition, oil that is retained in the source rock may be converted into natural gas and high carbon solids $[2,3,4,5,6,7,8]$.

\subsection{Maturation of organic matter in shales}

The amount of oil and gas released during kerogen maturation depends on the chemical composition of kerogen, which depends in turn on the organic matter from which it was formed and the biochemical 
transformation that it underwent at shallow burial depths. Type I kerogen has the highest $\mathrm{H} / \mathrm{C}$ ratio, it is formed from lipids and other organic matter (primarily in lacustrine sediments), and it has the highest oil generation potential. Type II kerogen is sourced primarily from planktonic marine organic matter. Type III kerogen, which has a lower $\mathrm{H} / \mathrm{C}$ ratio than type II kerogen, is derived primarily from terrestrial organic matter, and it produces mainly natural gas. Type IV kerogen has the lowest $\mathrm{H} / \mathrm{C}$ ratio, and it is not a significant source of hydrocarbon. Type II kerogen is the most important source of oil and natural gas. Methane is also produced by microbial activity at shallow burial depths. This is an important source of natural gas, but little of this gas is retained with the kerogen as it is buried to depths at which oil production occurs [7].

\subsection{The onset of micro-fracturing and migration of organic matter}

Several studies have correlated source rock maturation with petroleum migration, and early work is discussed in thorough reviews of primary migration $[9,10,11]$. Some investigators have used field observations to support the idea that microfractures serve as primary migration pathways $[12,13,14]$. Laboratory experiments also suggested that kerogen transformation leads to the formation of bed parallel microfractures. Propagation of these microfractures is controlled by the anisotropy of mechanical properties and the orientation of kerogen patches in the source rock [15, 16]. Lash \& Engelder [17] found microfractures that were filled with material which had chemical characteristics similar to those of decomposed kerogen. Observations of microfractures filled with calcium sulphate and organic materials [18] and horizontal microfractures at depths of 3.8-5 km have been reported [13]. Also, further studies of the conditions and processes that govern the dynamics of microfracture formation pointed towards a subcritical fracture propagation mechanism, because the transformation of kerogen to petroleum cannot increase the pressure in microfractures rapidly enough to drive critical fracture propagation. The rate of fracture propagation is governed by the chemical kinetics of fluid production during kerogen maturation [19], and while microscopic fracture propagation at high velocities, by a series of small jumps, has not been ruled out, chemically mediated fracture propagation (stress corrosion fracturing) appears to be more likely.

When kerogen is converted into oil, natural gas and other fluids, there is a net volume increase of about $10-20 \%$ under the prevailing temperature and stress conditions, and the resulting pressure is high enough 
to fracture the source rock and drive sub-critical microfracture propagation [20]. It has been proposed that microfractures play an important role in primary oil migration by providing pathways for fluid transport $[13,14,15,17,18,21,22,23]$. The microfractures formed by kerogen maturation tend to propagate along the laminations and bedding-parallel surfaces [16]. Based on linear elastic fracture mechanics theory, a mode I (opening mode) fracture propagates normal to the direction of the minimum principal stress, provided that the medium is isotropic [15]. At depth greater than $\approx 1 \mathrm{~km}$, the largest principal compressive stress is usually the vertical lithostatic stress, and the least principal compressive stress lies more-or-less in the horizontal plane [24, 25]. Since rocks are very weak materials under tensile stress, hydraulic fracturing is expected to occur preferentially along a vertical plane oriented perpendicular to the direction of the least principal compressive stress, and this is taken advantage of in high volume hydraulic fracturing to increase oil and gas production. However, on very small scales, strength effects become much more important and the local stress and pressure may deviate substantially from the large scale far field stress. Localized fluid production processes, such as the maturation of kerogen patches, changes the local stress state resulting in effective minimum principal stress that is perpendicular to the plane of lamination $[26,27,28]$. Because the kerogen concentration is higher in some laminae than others [17] and because of the high degree of structural and mechanical anisotropy that arises because of this lamination, orientation of anisometric particles such as stacked clay platelet aggregates during sedimentation and the increase in orientation that occurs during compaction, the strength and fracture toughness of many shales are much smaller for fractures parallel to the bedding plane than perpendicular to it $[11,15,17]$.

\subsection{Propagation of microfractures and primary migration}

Propagating microfractures may coalesce, and when they reach pre-existing vertical fractures, that are open, partially healed or healed but weak, a three-dimensional fluid conductive fracture network that facilitates hydrocarbon primary migration may be formed. Because coalescence with pre-existing open or weak vertical fractures changes the stress field at the fracture tip, and the fluid pressure often decreases, propagation of the part of the horizontal fracture that reaches the pre-existing vertical fracture may cease [19]. A hydraulic fracture may propagate around a pre-existing fracture, and the parts of the fracture front that propagate around the pre-existing fracture may re-join behind it giving the false 
112 impression that the hydraulic fracture propagated through the pre-existing fracture. Microfractures

113 formed by fluid production (natural micro-scale hydraulic fractures) may be expected to close when the

114 fluid in them escapes to connected microfractures or pores more rapidly than the rate of fluid production

115 within them. Even if microfractures become completely non-conductive because they become filled

116 with minerals and/or bitumen, because of pressure solution creep or for other reasons, they may remain

117 mechanically weak and, as demonstrated in analog experimental systems, they may become re-opened

118 as fluid production continues once enough fluid has penetrated into them and the pressure of the fluid

119 becomes high enough to drive fracturing [29].

\subsection{Experiments of primary migration}

121 In the present study, we designed a system that enables very small hydrocarbon release events to be 122 tracked during the maturation of immature Green River shale (a marlstone rich in type I kerogen) 123 samples, by using pressure sensors with a time resolution in the order of $0.01-1$ milliseconds. The main goal was to experimentally characterize the fluid expulsion events, some of which are attributed to the appearance of microfractures at different heating temperatures. We determined whether weaker fluid expulsion events occurred at lower temperatures and whether these expulsions grew in size or in number as the temperature was raised. A persistent behavior in the fluid expulsion events that occurred at a constant elevated temperature was observed, and a conceptual model is proposed. We determined how much gas on average was released during the process. Preliminary analysis of the fluid expulsion data indicated that power law relationships might exist between several variables, and this was eventually verified for one of them (the probability distribution of burst amplitudes, where a burst consists of a set of pressure pulses closely spaced in time). We address how confinement affects the rock fracturing behavior. A series of specifically-designed experimental studies of fluid expulsion and development of

134 microfracture networks and their contributions to the flow of hydrocarbons in the primary migration process are discussed. 


\section{MATERIALS AND METHODS}

\subsection{Sample preparation and sample holder}

Cylindrical core samples, $25 \mathrm{~mm}$ or $28 \mathrm{~mm}$ in diameter and with aspect ratios (length/diameter) of 0.6 and 1 respectively, were drilled from a Green River Shale block. This rock is an immature marlstone, which contains type I kerogen [30]. Previous experiments have shown that kerogen maturation at atmospheric pressures occurs in this organic rich rock on time scales that are convenient for laboratory experiments $(1-10$ days $)$ at temperatures in the $300-350^{\circ} \mathrm{C}$ range [16]. The sample dimensions and experimental conditions that were used for system calibrations and kerogen maturation experiments are provided in Table 1. The smaller diameter samples were placed inside a sample holder (Figure 1), which has the same dimensions as the inner space of the autoclave. The larger samples, which are of the same diameter and height as the inner space of the autoclave chamber, were placed directly inside the autoclave. The steel sample holder was custom-made to provide passive confinement of the Green River Shale cylinders. As the temperature was increased, the difference between the thermal expansion of the shale sample, which initially fits tightly inside the holder, and the smaller expansion of holder itself, generated a passive confining stress. Based on the thermal expansion coefficient of Green River Shale $\left(55 \times 10^{-6} /{ }^{\circ} \mathrm{C}\right.$ in the vertical direction, perpendicular to the bedding plane, and $25 \times 10^{-6} /{ }^{\circ} \mathrm{C}$ in the horizontal direction, parallel to bedding [16]), the directional average of its slightly anisotropic Young's modulus 25.0 GPa (about $26 \mathrm{GPa}$ parallel to the bedding plane and about $23 \mathrm{GPa}$ perpendicular to the bedding plane) [31]), and the thermal expansion coefficient of the stainless steel -AISI 302- that the sample holder was fabricated from $\left(\approx 18 \times 10^{-6} /{ }^{\circ} \mathrm{C}\right)$ and its isotropic Young's modulus (180 GPa), we estimated that the maximum confining stress in the direction parallel to the lamination plane was on the order of $100 \mathrm{MPa}$. However, this estimate does not take into account the thermal decomposition of the kerogen and temperature sensitive inorganic minerals, the production of fluids during these thermochemical processes or the loss of fluids from the sample holder in the higher parts of the temperature ranges used in the experiments. Twelve holes were drilled into the steel holder as conduits for the fluids released during the experiments. Wave springs with a spring force of $108 \mathrm{~N}$ maintained a minimum axial compressive stress on the order of $0.18 \mathrm{MPa}$ on the $28 \mathrm{~mm}$ diameter samples and the sample holder bolt maintained a minimum axial load of $2 \mathrm{MPa}$ (clamping force) on the $25 \mathrm{~mm}$ diameter 
samples providing that the shale sample does not contract too much from conversion of immature

kerogen into denser high carbon material and fluids that are allowed to escape. To avoid deformation of the springs during the experiments, they were annealed at $500^{\circ} \mathrm{C}$. After annealing, the springs held their shapes much better at high temperatures, and the minimum axial load can be considered to remain moreor-less constant during the experiments.

\subsection{Experimental setup}

The samples and the holders were placed inside an autoclave (Premex ${ }^{\mathrm{TM}}$ reactor), which had three inlet/outlet ports (Figure 1). Two kinds of pressure measurement setups were used. In the first setup, one port was connected to an analogue pressure gauge and another to a digital static pressure transducer (Gems $^{\mathrm{TM}}$ 3500-psi pressure transducer) that was connected to a data acquisition device (micro controller National Instruments CompactRio ${ }^{\mathrm{TM}}$ platform). The static pressure data and temperature were recorded at $1 \mathrm{~Hz}$. The third port was connected to a nitrogen or carbon dioxide gas cylinder to apply a fluid pressure in the system. In the second setup, the port, which was used to pressurize the setup at the beginning of each experiment, was connected to a precise differential pressure sensor (Kistler Model 7031 quartz piezoelectric pressure sensor), and the remaining outlet port was used to pressurize the system at the beginning of each experiment, and then record the static pressure during the experiment. This differential piezoelectric pressure sensor recorded quasi-static pressure variations up to $25 \mathrm{MPa}$ [32] with a sensitivity down to $\approx 0.354 \mathrm{kPa}$, while its built-in accelerometer compensated dynamic interference signals produced by shocks or vibrations, such as acoustic emissions generated by fracturing within the Green River Shale sample (or any form of outside interference). This sensor was connected to a single channel laboratory charge amplifier (Kistler's 5018a) for signal conditioning and amplification of the piezoelectric pressure sensor and conversion to a proportional low-impedance voltage signal. This charge amplifier was connected to a data acquisition device (micro controller National Instruments CompactRio ${ }^{\mathrm{TM}}$ ) (Figure 1). The data acquisition frequency for some experiments was $500 \mathrm{~Hz}$ which was later reduced to $20 \mathrm{~Hz}$, by averaging over intervals of $0.05 \mathrm{~s}$ ( 25 data points), or to $1 \mathrm{~Hz}$ for other experiments conducted later by sampling over intervals of $1 \mathrm{~s}$. The experiments lasted between 2 and 12 days, during which time hydrocarbon gases and liquids were produced by maturation of the kerogen. In each experiment, a monotonic increase in pressure due to gas production was recorded 
by the static pressure transducer, while the differential pressure transducer recorded pressure pulses

193

194

195

196

197 caused by small rapid gas release events. Elevated temperatures reduce the internal resistance and sensitivity of the piezoelectric transducer so it was placed at the end of a line instead of close to the sample. The differential pressure transducer recorded pressure pulses related to short term gas release events, whereas the static pressure transducer recorded the long term pressure increase due to gas production (the contributions of both continuous gas release and pulses).

Several test experiments were conducted to select the charge amplifier control parameters. The discharge time was set at 42 seconds based on the build-up rate of the largest peak. A range (maximum pressure fluctuation registration) of $354 \mathrm{kPa}$ and a sensitivity charge of $61.24 \mathrm{pC} / \mathrm{bar}$, which makes each volt registered equivalent to $35.4 \mathrm{kPa}$ were chosen. Consequently, the voltage signal has the same frequency content and phase as the differential pressure, though it has different amplitudes.

For both setups, the system was pressurized and calibrated to establish sample-free temperature and pressure base-lines prior to conducting the experiments with samples and insulated to reduce fluctuations in the autoclave temperature caused by cycling of the heater. Before each experiment, the equipment was tested to ensure that there were no leaks large enough to affect the experiment. Because there was significant heat loss from the space between the heater and the autoclave, the temperature inside the autoclave chamber was lower than the temperature of the heater. A Thermo Scientific MultiBlok $^{\mathrm{TM}}$ heater (see Figure 1) thermostat activated the heating mechanism when the heater's temperature dropped by $1^{0} \mathrm{C}$. However, the temperature fluctuations in the autoclave chamber were several degrees higher and this resulted in pressure fluctuations on the order of $1 \%$. To reduce this fluctuation and also the heat loss, the space between the heater and the autoclave was filled with silica powder and covered by layers of glass wool for experiments 1-8 and filled with glass beads for experiments 9-13. Silica powder has a substantially lower thermal conductivity than the body of the autoclave and helps to retain the temperature of the autoclave better when the heater switches off.

\subsection{Kerogen maturation experiments}

A total of thirteen independent experiments were carried out with different objectives (see Table 1): 1) In the first experiment, the release of hydrocarbon during maturation of a $28 \mathrm{~mm}$ diameter shale sample was studied at a temperature of $350^{\circ} \mathrm{C}$ and an initial differential stress of $175 \mathrm{kPa}$, imposed by a wave 
spring. Because of the large thermal expansion coefficient of the Green River Shale relative to that of

221

222

223

224

225

226

227

228

229

230

231

232

233

234

235

236

237

238

239

240

the steel sample holder, the axial stress may have increased substantially - to values on the order of 100 $\mathrm{MPa}$ as the sample is heated. However, thermal decomposition of kerogen and temperature sensitive inorganic minerals, desorption of strongly sorbed water and escape of at least part of the fluids generated by thermal decomposition at $350^{\circ} \mathrm{C}$ make it impossible to estimate the confining stress during the later stages of the experiment. 2) In the second experiment, conducted without a Green River Shale sample, the temperature was controlled at $350^{\circ} \mathrm{C}$ and the system fluid pressure was allowed to increase to characterize the fluctuations in temperature and pressure when the heater activated and deactivated. 3) The third experiment was conducted at a constant temperature of $350^{\circ} \mathrm{C}$ with a $25 \mathrm{~mm}$ sample inside the sample holder and an initial differential stress of $2 \mathrm{MPa}$ (clamping force of the sample holder bolt). 4) The fourth experiment was conducted on a large sample ( $28 \mathrm{~mm}$ diameter $)$ at a temperature of $350^{\circ} \mathrm{C}$ and initial differential longitudinal (axial) stress of $175 \mathrm{kPa}$ to study fracture network generation. The pressure variation in the experiments 1-4 was monitored with a linear response membrane pressure sensor. 5) Experiment 5 was conducted at a temperature of $252^{\circ} \mathrm{C}$ and an initial differential stress of 2 $\mathrm{MPa}$, and the differential piezo-electric pressure transducer was used to better detect small pressure variations related to hydrocarbon expulsion events (which are likely related to formation of microfractures). 6) Experiment 6 was conducted at a temperature of about $300^{\circ} \mathrm{C}$ and an initial differential stress of $175 \mathrm{kPa}$ to investigate larger fluid expulsion events and induced micro-fracturing. 7) In experiment 7 conducted at an initial differential stress of $2 \mathrm{MPa}$, the temperature was increased in six steps over the course of the experiment, from room temperature to $211^{\circ} \mathrm{C}$ and then to $237^{\circ} \mathrm{C}, 255^{\circ} \mathrm{C}$, $271^{\circ} \mathrm{C}, 301^{\circ} \mathrm{C}$ and finally to $319^{\circ} \mathrm{C}$. 8) Experiment 8 was conducted with an initial differential stress of $2 \mathrm{MPa}$ during three stages: at a temperature of $252^{\circ} \mathrm{C}$, then at room temperature $\left(28^{\circ} \mathrm{C}\right)$ and finally back to a temperature of $252^{\circ} \mathrm{C}$. During the middle stage at $28^{\circ} \mathrm{C}$ the effectiveness of the acoustic emission cancelation mechanism of the piezoelectric sensor was investigated and a base-line signal was determined. Although the piezoelectric sensor used for differential pressure measurements had an internal mechanism for cancelation of shocks or vibrations generated by acoustic pressure waves (also known as sound pressure and acoustic emission), the effectiveness of the mechanism over a broad range of frequencies was uncertain. This uncertainty in the sensitivity of the sensor to acoustic emissions was 
addressed by pre-experimental dry-run tests. In experiment 8 the sample inside a holder was covered

with silica powder to suppress any acoustic emissions (through the solids or the gas).

Experiment 12 tested the repeatability of the results, and it was conducted under exactly the same conditions as experiment 11.13) Experiment 13 was an experiment with no confinement. In experiments 9 through 13, the data capture frequency of the differential pressure transducer was reduced to $1 \mathrm{~Hz}$ from $500 \mathrm{~Hz}$ (Table 1). Except for experiments 7 and 8, the temperature was increased rapidly, and then maintained at an essentially constant value for the duration of the experiment.

The raw data of experiment 5 are shown in Figures 2 and 3. The temperature was nearly constant at around $252^{\circ} \mathrm{C}$, with small fluctuations of $\approx 1^{\circ} \mathrm{C}$, caused by the switching on and off of the heater (Figure 3a). During the experiment, the fluid pressure inside the autoclave increased with time due to hydrocarbon production (Figure $3 b$ ). The evolution of the P/T ratio over time in experiment 5 (Figure 2a), shows jumps due to cycling of the heating system and a linear trend that corresponds to increased pressure due to hydrocarbon production and release from the Green River Shale sample. The differential pressure sensor (Figure 3c) detects individual pressure pulses. Because the natural discharge of the piezoelectric sensor in the differential pressure sensor results in a decrease in voltage whenever there is a pressure pulse, there is a positive change in the slope of the voltage signal. As multiple pulses can contribute to the shape of the voltage peaks, the entire time interval during which the voltage remains above the noise threshold (the maximum amplitude of the baseline experiments) is considered to be a single pressure burst (a set of pressure pulses closely spaced in time) irrespective of how the voltage varies during this interval. Figure $4 \mathrm{a}$ shows the measured temperature during an experiment that was designed to increase the temperature in steps and figure $4 \mathrm{~b}$ shows the measured temperature in experiments that were designed to maintain constant temperatures after an initial rapid heating stages. All of these experiments lasted for several days, and Figures $4 \mathrm{a}$ and $4 \mathrm{~b}$ show that while the temperature deviated from the planned temperatures during these experiments, the deviation was almost always $\leq$ than the planned temperature. 
We determined which frequencies were the most dominant in the time series of the differential pressure,

276

277

278

279

280 by calculating the Fourier power spectra. Figure 5 shows the results of these analyses on bi-logarithmic scales for a reference experiment in which no heating was applied (Figure 5a) and experiment 7 for which six consecutive temperature increases were applied (Figure $5 b$ ). The peak at a frequency of $2 \times 10^{-}$ ${ }^{2} \mathrm{~Hz}$, corresponding to a period of $50 \mathrm{~s}$, is close to the relaxation time of $42 \mathrm{~s}$ chosen for the differential pressure sensor. Consequently, frequencies higher than this value are disregarded. For frequencies smaller than the peak frequency, there is uncertainty concerning the existence of characteristic peaks in Fourier power spectra that would show a periodic behavior in the experiments.

\subsection{Data pre-processing}

The data were pre-processed to ensure that pressure and temperature signals have the same time origin and determine which part of each signal is related to a physical process in the sample and which part is related to the electronics noise and experimental drift caused by pressure leaks if any, and other processes. To ensure that there is good conformity and time synchronization between the static and differential pressure signals, we compared specific pressure pulses of experiment 5 . The correlations in time between the pressure pulses and the discrete rises in static pressures are shown in Figure 6. The static pressure signals were first detrended and normalized by subtracting their respective moving averages for comparison with the differential pressure pulses. Because the two pressure transducers signals were recorded on different acquisition systems, sometimes they were not synchronized and time synchronization of both signals was necessary before processing the data. This was done by calculating the cross-correlation between these two signals and correcting them by using the time delay (phase shifts) obtained from the cross-correlation.

For the differential sensor data, only pressure fluctuations that exceeded a noise threshold were considered (Figure 6d). The noise level was determined by: a) operating the system in isolation when it was not connected to the setup, b) by means of one sample-free experiment, and c) when there was a sample but no heating. The noise level was not sensitive to the temperature imposed during the experiments.

After applying the noise threshold, the signal consisted of a time series of pressure pulses during which the pressure remained above the noise threshold separated by time intervals during which the pressure 
remained below the same noise threshold. The amplitudes of the pressure bursts and inter-event time intervals were then extracted for statistical analyses. Unlike the digital static pressure transducer, the differential pressure transducer can record individual (or multiple) hydrocarbon release events separated in time by more than the reciprocal of its curtailed data-capture frequency $\left(0.02 \mathrm{~s}^{-1}\right)$.

\section{RESULTS}

The experimental results enabled relationships between heating temperatures and kerogen decomposition coupled to fluid expulsion and/or micro-fracturing to be established.

\subsection{Liquid hydrocarbon release and fracture network development}

At the end of experiment 1 , in which a Green River Shale specimen was held at a temperature of $350{ }^{\circ} \mathrm{C}$ for two days, a hydrocarbon layer with an average thickness of $3 \mathrm{~mm}$, which was solid at room temperature, coated the outer part of the sample, and this provided evidence for liquid hydrocarbon release (Figure 7a). Also, at the end of experiment 3, which lasted longer than experiment 1, deposition of darkly colored hydrocarbon on the outer wall of the sample holder and the inner wall of the autoclave vessel indicated more copious hydrocarbon production (Figure 7b). After experiment 4 was run for six days, some horizontal (parallel to laminations), deviated and vertical fractures of various sizes could be seen on the surface of the sample (Figure 7c). The microfracture pattern was similar to that observed by X-ray tomography (Figure 7d-f). The corresponding pressure time series included two major events resulting in a lasting increase and decrease in pressure, as well as multiple pulses.

\subsection{Pressure variations during shale maturation}

Experiments 1-4 provided information about the cumulative effect of many hydrocarbon expulsion events associated with the production of hydrocarbon (Figure 7a-b). Because the digital static pressure transducer used in these experiments was not sensitive enough, and it had an insufficiently short response time, little information concerning the dynamics of individual fluid expulsion events was obtained. In experiments 5 to 13, the differential pressure transducer was used in addition to the digital pressure transducer. When the pressures recorded by the digital pressure transducer and the differential pressure transducer are compared (Figure 3), it can be seen that some large fluid expulsion events are recorded as steps in the static pressure. Experiments 9 to 12 differ only from experiment 5 in having 
been conducted at higher temperatures. During experiments 9-12 there were fewer peaks in the differential pressure signal and a lower total static pressure after the temperature at which the experiments were conducted was decreased. Comparing experiment 13 with no confining stress conducted at $305{ }^{\circ} \mathrm{C}$ and experiment 10 conducted at $292{ }^{\circ} \mathrm{C}$ with confinement, both of which were run for 4 days, the static pressure during experiment 13 rose by $1.6 \mathrm{MPa}$ while the static pressure during experiment 10 rose by about $1 \mathrm{MPa}$. Since the maturation of kerogen and the cracking of high molecular mass hydrocarbons are volume increasing processes, an increase in compressive stress is expected to suppress these processes and reduce the volume of gas produced. However, pressures that occur at depths less than $10 \mathrm{~km}$ (less than $\approx 250 \mathrm{MPa}$ ) are believed to play a secondary role relative to temperature [6].

After achieving temperature stability in the system during experiment 5 (Figure 3a), the pressure continued to increase although at a far smaller rate (Figure 3b). Figure $3 \mathrm{c}$ shows the data recorded by the differential pressure transducer after the temperature reached $250^{\circ} \mathrm{C}$ (after about 6000 seconds) and an essentially constant temperature of $250-253^{\circ} \mathrm{C}$ was maintained until the pressure pulses ceased after about $1.55 \times 10^{5}$ seconds. A similar pattern was observed in experiment 7 for the six different autoclave temperature steps: $211{ }^{\circ} \mathrm{C}, 237{ }^{\circ} \mathrm{C}, 255{ }^{\circ} \mathrm{C}, 271{ }^{\circ} \mathrm{C}, 301{ }^{\circ} \mathrm{C}$ and $319{ }^{\circ} \mathrm{C}$ (Figure 4a). Experiment 7, in which pressure pulses appeared continuously as the temperature was increased in five consecutive steps, demonstrates that kerogen maturation was not complete during this experiment.

Figure 8 shows the probability distribution functions (PDF),complementary cumulative distribution function $(\mathrm{CCDF})$ and cumulative distribution functions $(\mathrm{CDF})$ of the pressure burst waiting times, $\Delta \mathrm{t}$, (the time intervals between successive pressure bursts with amplitudes greater than the noise threshold) for experiments 5, and 9 to 13 . The data displayed in Figure 8 indicate that the frequency of waiting times decreases monotonically with increasing waiting time. In some cases there is weak evidence for a power law distribution of waiting times using the linear regression method, and in other cases the data suggests that there might even be two power law regimes. However, the range of apparent power law scaling is small (less than a range of two decades in the waiting times), and on a log-log scale, the data can also be represented by a curve with a slope that changes continuously as the waiting time changes. The evidence for a power law distribution of waiting times is strongest for short waiting times, and the 
effective power law exponents vary from -1.5 to -3 . It is not clear why the effective exponents vary so

much from one experiment to another, and this casts doubt on the existence of a fundamental cause of the apparent power law distribution of waiting times in some of the experiments. Application of the goodness-of-fit method [33] further confirms this conclusion because the p-values, which quantifies the plausibility of the power law hypothesis, is greater than 0.1 over only a very limited range of data (<one decade). If the p-value is less than 0.1, a power law is considered to be inconsistent with the data [33]. In Figure 9a and 9b linear fits to the complementary cumulative distribution (tail distribution) of the burst amplitudes (amplitude of the pulse that has the highest amplitude of all the pulses in the burst) for all the bursts with amplitudes above the noise floor are shown on a log-log scale for several experiments: i) experiment 8 , during which the shale was heated at six successively increasing temperatures over a period of two days (12 days in total), ii) experiments 9 through 13 which were conducted at different temperatures ranging from $275{ }^{\circ} \mathrm{C}$ to $310{ }^{\circ} \mathrm{C}$. The pressure burst amplitudes were normalized by dividing them by the noise threshold. Figure 9 suggests that for the larger burst amplitudes the distribution of burst amplitudes can be represented by a power law. For experiment 7, the distribution of burst amplitudes can be represented by a straight line on a log-log scale with a slope of $-3.5 \pm 0.3$ at $211^{\circ} \mathrm{C}$ for a total of $9 \times 10^{4}$ bursts. This slope increases to $-2.6 \pm 0.1$ at $319^{\circ} \mathrm{C}$ for $1.2 \times 10^{5}$ bursts (Figure 9a, Table 2). The fitting was performed using a goodness-of-fit method [33], which allows the slope of a power law on a log-log scale (the exponent), the error of this slope, and the range of bursts sizes over which the power law fit is reliable to be determined (Figure 9 and Table S2). In experiment 7, in which the temperature was increased in steps (Figure 4a) the rate of pressure increase, measured by the digital static pressure transducer, was the smallest at the lowest temperature of $211^{\circ} \mathrm{C}$ and the highest at the highest temperature of $319{ }^{\circ} \mathrm{C}$. However, during kerogen maturation at the four intermediate temperatures, the rate of pressure increase did not depend significantly on the temperature.

In experiment 5 , the rock sample had a volume $V_{\text {rock }}=7.4 \times 10^{-6} \mathrm{~m}^{3}$ and the autoclave chamber a volume of $V_{\text {aut }}=25 \times 10^{-6} \mathrm{~m}^{3}$, the increase in static pressure was primarily a consequence of expulsion of gas from the shale sample into the space between the sample and the inner wall of the autoclave chamber. However, changes in the volume of the sample, including the fluids trapped within it may have a small effect. Disregarding the part of the signal during which the temperature was 
increased, Figure 2 shows that the pressure/temperature ratio, $\mathrm{P} / \mathrm{T}$, increases linearly with time with a slope of $\alpha=2.8 \times 10^{-3} \mathrm{~Pa} /(\mathrm{K} \times \mathrm{s})$ and a $\mathrm{y}$-axis-intercept of $29 \mathrm{kPa} / \mathrm{K}$. This is interpreted as an essentially constant rate of fluid production and expulsion during the early stage of catagenesis. For an ideal gas, the pressure/temperature ratio is given by

$$
\frac{P(t)}{T(t)}=\frac{n(t) R}{V}
$$

390

where $\mathrm{P}(\mathrm{t})$ is the pressure at time $\mathrm{t}(\mathrm{Pa}), \mathrm{T}(\mathrm{t})$ is the absolute temperature at time $\mathrm{t}\left({ }^{\circ} \mathrm{K}\right), n(t)$ is the number of moles of gas at time t, $\mathrm{R}$ is the gas constant $\left(8.31 \mathrm{~J} /(\mathrm{K} \times \mathrm{mol})\right.$ and $\mathrm{V}$ is the volume of the gas $\left(\mathrm{m}^{3}\right)$. Disregarding the volume of the sample holder walls, nitrogen-filled volume of the lines to the pressure gauges, the volume of gas inlet valve, the volume within the pressure gauges, volume between the sample and the autoclave chamber and the pore volume within the shale,

$$
\partial(P(t) / T(t)) / \partial t=\frac{(\partial n(t) / \partial t) R}{V_{\text {aut }}-V_{\text {rock }}}=\alpha,
$$

where $V_{\text {aut }}$ is the autoclave volume and $V_{\text {rock }}$ is the rock volume. Assuming no reduction in pressure due to condensation and using the observed time dependence of $\mathrm{P} / \mathrm{T}\left(\alpha=2.8 \times 10^{-3} \mathrm{~Pa} /(\mathrm{K} \times \mathrm{s})\right)$ it follows that

$$
\frac{\partial n(t)}{\partial t}=\frac{\alpha\left(V_{\text {aut }}-V_{\text {rock }}\right)}{R}=5.9 \times 10^{-9} \frac{\mathrm{mole}}{\mathrm{s}}
$$

Integrating over the $6.5 \times 10^{5} \mathrm{~s}$ duration of experiment 5 , the catagenesis produced $3.8 \times 10^{-3}$ mole of gas from the sample. The amounts of gas released during experiments 9 through 13 were similar to the amount released during experiment 5, but the rate of gas release prior to temperature stabilization was higher because instead of silica powder and glass wool, glass beads (a poorer insulator) was used to insulate the sample and thus suppress temperature fluctuations and therefore the amount of gas released after temperature stabilization was lower. However, as expected, the gas release rates were higher for higher heating temperatures (Table 1). The formation of hydrocarbon coatings on the sample holder (left) and inner wall of the vessel, which was solid at room temperature, suggests that thermal cracking of higher molecular mass hydrocarbons probably occurred after fluid had been expelled from the Green River Shale and that part of the pressure increase may result from gas formed during this cracking process. This would contribute to the continuous production of gas, but not to the pressure pulses. 
410 The thresholded differential pressure signal time series was analyzed to determine if there was any 411 persistent behavior. First a linear trend in the signal was removed and then the contribution of the pressure pulses to the cumulative pressure increase was calculated from the running sum of the peak areas. A rescaled range (R/S) analysis was then conducted by calculating the ratio $R / S$, where $\mathrm{R}$ is the range of the cumulative de-trended pressure and $\mathrm{S}$ is the standard deviation of the cumulative de-trended pressure relative to its average, both measured over the same time window $\Delta \mathrm{t}$ and averaged over all possible time windows within the time series [3435]. If the cumulative time series is a self-affine fractal, then $\mathrm{R} / \mathrm{S}(\Delta \mathrm{t}) \approx \Delta \mathrm{t}^{\mathrm{H}}$, where $\mathrm{H}$ is the Hurst exponent. If $0.5<\mathrm{H} \leq 1$, the cumulative de-trended signal is persistent and if $0 \leq \mathrm{H}<0.5$, it is anti-persistent.

In the context of this work, persistence implies that large pulses are more likely to be followed by large pulses than by small ones and that small pulses are more likely to be followed by small ones, and the pulse size correlation is long-ranged in time. This may indicate that relatively large volumes of gas accumulate inside the Green River Shale samples (in large inflated fractures and/or fracture networks) followed by the expulsion of all or part of the accumulated fluid controlled by the opening and closing of fractures. Persistent behavior was observed in the detrended (and normalized) static pressure signal and discrete pulses (Figure 6d). Figure 10 shows plots of $\log _{10}(\mathrm{R} / \mathrm{S})$ versus $\log _{10} \Delta \mathrm{t}$ and Hurst exponent values for the differential pressure signals of experiments 5 and 7. The R/S statistics were calculated using the method of Di Matteo [36]. The Hurst exponents obtained from the R/S analyses of the pressure time-series are significantly larger than 0.5 , indicating that there is quite strong pressure pulse size persistence. To unravel the contributions of pressure pulse sizes and the time intervals to the persistence, $\mathrm{R} / \mathrm{S}$ analysis was also conducted on the detrended $\mathrm{P}(\mathrm{t})$ signal, where $\mathrm{P}(\mathrm{t})$ is the accumulated pressure at time $t$ and on $\mathrm{N}(\mathrm{t})$, where $\mathrm{N}(\mathrm{t})$ is the number of pulses that have occurred up to time $\mathrm{t}$. This exercise also resulted in Hurst exponent values around 0.9 for the experiment 5 and six stages of experiment 7 . All these exponent values are larger than the value of 0.5 measured in the absence of a sample in the autoclave and indicate that i) time correlations exist in the system and ii) a persistent behavior occurs during gas expulsion. 
To conclude, the results show that during heating of immature shales, some hydrocarbon was produced and released in the autoclave. For all experiments, the gas pressure in the autoclave increased with increasing time when the temperature was high enough to drive hydrocarbon production. The differential pressure sensor enabled the dynamics of fluid production to be monitored in detail. These pressure pulses were intermittent, showed power law relationship in their size, the frequency of waiting times between them decreased monotonically with increasing waiting time and displayed a persistent behavior. Based on these data, a conceptual model for various stages of fluid expulsion is proposed below.

\section{DISCUSSION}

\subsection{Microfractures in shales}

During primary migration, microfracture formation is driven by the production of fluids (primarily hydrocarbons). These fractures and the connected fracture network formed from them plus the pore space act as pathways for fluid transport within the source rock and expulsion of fluid from it. Provided that the medium is isotropic, the fracture propagates normal to the direction of the minimal principal stress $[15,28]$. At depths greater than about $1 \mathrm{~km}$, the largest principal compressive stress is usually the lithostatic stress, in the vertical direction, and the direction of the smallest principal compressive stress lies more-or-less within the horizontal plane so that opening mode hydraulic fractures driven by fluid injection for geotechnical applications or natural fluid production are expected to grow preferentially along parallel vertically oriented planes. However, real rocks are heterogeneous on all scales, and deviation of the local stress from the large scale average stress (the far field stress) increases as the scale decreases. The transformation of kerogen into fluids and more mature kerogen (ultimately carbon) can change the local stress field, and the minimum principal stress becomes mostly lamination surface perpendicular. In situ X-ray tomography experiments have demonstrated that many fractures can nucleate and grow along lamination planes, which are usually more-or-less horizontally oriented in the subsurface and in experiments $[16,37,38,39,40]$. However, some substantially deviated and subvertical fractures were also formed (Figure 7d-f). Given the orientation of the flake-like kerogen patches and the strongly anisotropic shale fabric, it is very likely that horizontal fractures were the first to form as fluids were produced from the kerogen, and that they dominate during all stages of the shale pyrolysis. 
During pyrolysis experiments, fractures may become sealed by solid bitumen and/or char, and in the

464

465

466

467

468

469

470

471

474

475

476

477 subsurface at lower temperatures and on much longer time scales open cracks may become sealed in part or completely by both solid bitumen and inorganic minerals such as carbonates and sulphates and other mineral deposits as hydrocarbon fluids are being produced [16,17, 18, 37, 41, 42]. Although it has been proposed that vertical fracturing driven by the generation of hydrocarbon fluids from kerogen hydrocarbon generation is uncommon [20], strongly deviated and sub-vertical fracturing may occur because of the complex stress fields that occur during differential compaction and natural hydraulic fracturing, which may occur during the early stages of burial and diagenesis or during catagenesis. Kalani et al. [14] observed the presence of vertical microfractures in back shales from the Norwegian Continental Shelf and interpreted them as related to primary migration. Moreover, Goulart-Teixeira et al. [28] performed a numerical model study of the maturation of kerogen patches and proposed that a network of both horizontal and vertical fractures could form during primary migration.

Once a fracture has formed, it may remain a zone of weakness, and fracturing may be reactivated by an increase in pore pressure. In the experiments, the shale swells as the temperature increases, and if the sample wall touches the wall of the autoclave, the forces acting between the surface of the shale sample and the inner wall of the autoclave will affect the stress field within the shale sample. This may be sufficient to change the balance between horizontal and vertical fracturing, and unusually large pulses may occur if fluid cannot flow between the sample surface and the inner wall of the autoclave, or if the fluid path along the interface between the sample and the autoclave is blocked for other reasons such as the deposition of solid bitumen or char formed by the cracking of expelled hydrocarbon. Under these circumstances, a large amount of fluid generation and pressure buildup, over a large time interval, may be required to drive vertical fracturing resulting in a large pressure pulse. Once a vertical fracture reaches the upper or lower surface, it may provide a conductive pathway for fluids injected into it from horizontal fractures.

The abrupt appearance of fluid expulsion at temperatures as low as $210{ }^{\circ} \mathrm{C}$ implies the production of fluid and the rapid creation of flow pathways between the interior of the heated shale samples and their surfaces at about this temperature. Although kerogen maturation commences as temperatures as low as $\approx 50^{\circ} \mathrm{C}$, on geological time scales, it seems unlikely that sufficient hydrocarbon fluid to drive fracturing 
was produced at temperatures of $\approx 210^{\circ} \mathrm{C}$ on the time scale of the experiments reported here. Fracturing at $\approx 210^{\circ} \mathrm{C}$ can be attributed to desorption of sorbed water, the production of water and/or $\mathrm{CO}_{2}$ decomposition of sodium bicarbonate and sodium sesquicarbonate dihydrate (nahcolite and trona) and other evaporate minerals, which are often abundant in Green River Shale. The expansion and/or evaporation of pore water and organic fluids that were present before heating may also contribute.

\subsection{Implications for hydraulic fracturing}

In the subsurface, the local direction of minimum principal compressive stress may strongly deviate from the direction of large scale minimum principal compressive stress, and this may facilitate the growth of deviated fractures. In high volume hydraulic fracturing used for applications such as increased production of oil and gas, a wealth of micro-seismic data demonstrates that fracturing does occur preferentially in the plane perpendicular to the direction of the least principal stress [43]. However, the resulting fracture surfaces are rough, the process zone near the advancing fracture front is complex, and the large scale direction of propagation does not imply that the microfractures, which may play an important role in the overall hydraulic fracturing process, have the same orientation as the large scale hydraulic fracture.

\subsection{Dynamics of microfracturing during heating in shales}

During the heating process fluids are produced continuously. Some of them flow slowly through the low permeability porous medium into the space surrounding the sample. Kerogen maturation reduces the volume of solid and some of the fluids produced drives microfracturing. The permeability is expected to increase if the confining stress is not high enough to prevent it. Fluid production and expulsion from

511 the shale results in an increase in the pressure of the fluid surrounding the shale sample, and this is

512 recorded as pressure pulses superimposed on a continuous pressure increase. Our experimental results

513 are consistent with the idea that some of the gas flows rapidly into the space surrounding the sample

514 when fluid under pressure within the shale is expelled via the fracture network. Poroelastic pressure diffusion also contributes to the increase in the pressure of the fluid in the space surrounding the sample, and the pressure increases monotonically via a pressure ramp with brief periods of rapid pressure 
increase which we called pulses. The validity of this interpretation is supported by the static pressure profile (Figure 3).

519 Evidence for power law distribution of the burst amplitude was obtained, which points at their scalefree behavior. Irrespective of temperature and other conditions, and despite the enormous difference in time scales (our experiments were run for 2 to 12 days whereas maturation in nature lasts for millions of years) we believe that the experiments reported here do provide insight into primary migration and that essentially the same mechanisms are at work across a range of different scales and conditions including processes at work in the subsurface during the generation and primary migration of oil and gas.

Two types of fluid expulsion events were observed in the experiments. One is the large fluid expulsions events, which are likely to be associated with fracturing, and the X-ray tomography images provide direct evidence for fracturing. There is also a second family of far smaller fluid expulsion events which was only detectable through the differential pressure transducer records. At the beginning of a representative experiment (experiment 7) clusters of peaks are formed very close spaced in time, while towards the end more peaks are formed, but they more evenly separated in time. Although most of the Green River Shale is thermally immature, and it has produced little or no oil, the more deeply buried parts have generated some oil [3], and the Green River Shale may become an important source rock far in the future. The formation of microfractures would facilitate migration through the Green River Shale of the large amounts of fluid produced by thermal decomposition of kerogen and its expulsion into the surrounding rocks, and the presence of abundant microfractures, which are oriented mostly horizontally (but also diagonally and vertically), is necessary to produce a 3D connecting network $[12,13]$. Small fluid expulsion events also occurred at different temperatures in our experiments. At temperatures below $200^{\circ} \mathrm{C}$, they can be attributed to dehydration, the decomposition of sodium bicarbonate and sodium sesquicarbonates dihydrate (nahcolite and trona) and other evaporate minerals which are often abundant in Green River Shale. At higher temperatures, they are related to

542 organic matter maturation. It would take some time for sufficient fluid production by kerogen 543 decomposition to increase the fluid pressure and volume sufficiently to drive the formation of new 544 microfractures. Alternatively, local fluid pressure increase could reopen and reactivate previously 
formed, but closed, microfractures. Pressure release and fluid expulsion could also occur through connected pore volumes in the Green River Shale. However, the permeability of Green River Shale is very low $\left(\approx 10^{-7} \mathrm{mD}\right.$ and $\approx 10^{-8} \mathrm{mD}$ in the bedding-parallel and bedding-perpendicular directions respectively $[44,31,44])$. Increased porosity and permeability caused by a decrease in solid volume due to the decomposition of kerogen and minerals such as trona and nahcolite could provide pathways for fluid migration. The idea that microfractures play an important and probably dominant role in fluid migration and fluid expulsion during the maturation of organic rich shales is supported by the observation of microfractures filled with inorganic matter such as calcium sulphate and solid organic matter $[18,17]$. However, in the case of microfractures filled with inorganic minerals, the force of crystallization may have opened closed fractures.

\subsection{Conceptual model of hydrocarbon expulsion during primary migration}

In recent studies $[29,45]$, we proposed an analogy between primary migration and the behavior of a fracture network that formed in a simplified and homogeneous hydrogel with internal gas production. These experiments were performed using yeast fermentation in a Hele-Shaw cell, which generated the $\mathrm{CO}_{2}$ that drove hydraulic fracturing of the gel $[29,45]$, a system that represented kerogen-decomposition and fluid expulsion in a shale. The dynamics of fracture opening, closing and coalescence to form a fracture network was characterized quantitatively, and a model that explains the observed behavior was proposed [29]. In these experiments, the deflation of $\mathrm{CO}_{2}$ filled fractures that reached the open boundary of the Hele Shaw cell was observed, and although the rate of gas expulsion was not measured, the frequency of fluid expulsion events was about $1 \mathrm{~Hz}$, and this behavior is a clear indication of fluid expulsion through open fractures.

The calculated Hurst exponents in the pressure signals of experiments 5 and 7 indicated strong persistency and trending $[36,46]$. It turned out that both the pressure pulse sizes and the time intervals contribute to the overall persistency. Models other than that proposed by Kobchenko et al. [29] have also been proposed to explain this behavior, which deviates strongly from the behavior expected if fluid expulsion is dominated by diffusive and Darcy flow fluid transport. Bons et al. [47] proposed a paradigm for the transport and accumulation of oil, gas, and metamorphic fluids based on the concept of selforganized criticality. According to this paradigm, systems in which fluid is being generated may evolve 
rapidly into a self-organized critical state in which rapid, non-Darcian, fluid transport is coupled with

574 hydraulic fracturing. However, our investigation of self-organized criticality was inconclusive.

575 Based on our experimental results, we propose a four stage scenario for fluid expulsion during the pyrolysis of Green River Shale under constant temperature conditions. These four stages are described in Figure 11. In the first stage (stage a) hydrocarbon fluid is produced and expelled from the Green River

578 Shale at a relatively high rate as the increase in static pressure and the large fluctuations in the differential 579 pressure signal indicate. The high fluid expulsion rates from the very low permeability shale are 580 facilitated by the nucleation and growth of microfractures (Figure 11a). In the second stage (stage b), the rate of fluid production remains high but decreases because the remaining, more aromatic, kerogen is more resistant to thermal decomposition and it has a smaller hydrocarbon production capacity. Because kerogen is derived primarily from detrital organic matter, the chemical nature of one kerogen particle may differ substantially from that of a neighboring kerogen particle, and kerogen is closely associated with inorganic mineral particles that may catalyze or inhibit catagenesis. Consequently, some kerogen particles may undergo chemical transformations leading to fluid production much more slowly than others under any particular $(\mathrm{P}, \mathrm{T})$ conditions and this may extend the range of temperatures or times over which relatively rapid fluid production occurs during maturation experiments. Nevertheless, the rate of fluid expulsion during stage $b$ is less than during stage $a$, and this is consistent with the expectation that, under constant temperature conditions, the rate of fluid production will decrease with

591 increasing time because the solid material that remains (more mature kerogen) has a smaller fluid 592 generation capacity and it is more resistant to thermal decomposition (Figure 11b). During the third 593 stage (stage c) the now more mature kerogen produces fluid at a smaller rate and the expulsion of fluid 594 becomes more intermittent (Figure 11c). The first two fluid expulsion stages are likely to be accompanied by the nucleation and growth of new microcracks. During stage b, some fractures close

596 while others nucleate and grow, and during stage c no new fractures are formed, but pre-existing

597 fractures close and re-open. In the final stage (stage d) the highly carbonaceous, very high maturity, 598 residual kerogen is no longer capable of generating significant volumes of fluid, and the fluid expulsion rate declines to very low levels(Figure 11d). 
During the early stages of kerogen maturation, the fluid produced by each kerogen particle may be

601

602

603

604

605

606

607

608

609

610

611

612

613

614

615

616

617

618

621

622

retained in the kerogen particle that produced it (in the form of sorbed hydrocarbon or hydrocarbon in closed pores within the kerogen). This will leaded to swelling of the kerogen particles that can be expected to drive the formation of localized fractures that are too small to detect by X-ray microtomography. As hydrocarbon fluid increases, the swelling of the kerogen particles will increase and the microfractures will grow. Eventually, fluid will be expelled from the kerogen particles and the microfractures will form a fracture network through which long-range fluid transport can occur.

\subsection{Implication for primary migration and microfracturing in natural shales}

In nature, petroleum generation occurs in the $60^{\circ} \mathrm{C}-150^{\circ} \mathrm{C}$ temperature range under anisotropic stress conditions. In an earlier investigation, we were able to observe evidence for petroleum generation from Green River Shale (in the form of fracture formation) only at temperatures between $300^{\circ} \mathrm{C}$ and $400^{\circ} \mathrm{C}$ at atmospheric pressures [16, 37]. Neglecting the differences in confining stress and heating schedules, this could be due to the resolution not being high enough to capture the formation of small microfractures (fluid expulsion occurred through microfractures that had aperture widths too small to detect by X-ray tomography). By measuring the expulsion of fluid from Green River Shale samples, we have now obtained indirect evidence for the formation of microfractures at significantly lower temperatures. While we were not able to demonstrate that pressure pulses are necessarily accompanied by the expulsion of fluid through fractures that are generated or opened by the increasing pressure of the fluid generated by kerogen decomposition, the existence of the pressure pulses does strongly suggest that fluid expulsion is coupled with the dynamics of individual fractures and fracture networks. Pressure pulses require rapid changes in the fluid production rate and/or rapid changes in permeability. Rapid changes in the rate of fluid production by kerogen maturation is not plausible and rapid changes in permeability without microfracturing and/or the opening and closing of fractures is very unlikely (large and rapid changes in the pore volumes in brittle materials would drive fracturing). We were able to detect fluid expulsion events at temperatures as low as $211^{\circ} \mathrm{C}$, and the abrupt appearance of fluid expulsion implies the rapid creation of flow pathways between the interior of the heated shale samples and their surfaces at about 
this temperature, which is some $150{ }^{\circ} \mathrm{C}$ higher than the temperature at which oil generation from kerogen

628

629

630

631

632

633

634

635

636

637

638

639

640

641

642

643

644

645

646

647

648

649

650

651

652

occurs on a geological time scales.

At higher temperatures, the chemical reactions that generate hydrocarbons are accelerated and in absence of pre-existing hydrocarbon migration pathways sufficient hydrocarbon can be generated to increase its pressure sufficiently to overcome the confining stress and the (relatively small) tensile strengths of organic rich rocks [13, 14, 21, 22, 18, 23].

\section{CONCLUSIONS}

Microfractures are believed to play an important role in primary migration, but a detailed understanding of primary migration, including how fracturing and fluid flow are coupled with each other and with other processes is still lacking. The very large difference in length scales and even larger difference in time scales (by a factor on the order of one billion) between primary migration in the subsurface and laboratory experiments makes interpretation of the experiments in terms of primary migration challenging and uncertain. These difficulties are compounded by the heterogeneity and variability of source rocks and the kerogen within them. Nevertheless, we believe that laboratory experiments can play an important role in the development of a better understanding of primary migration. Under some natural conditions, such as when magma intrudes into sedimentary basins, accelerated maturation occurs, and study of source rocks that have undergone maturation under these conditions could help in bridging the gap between maturation in laboratory experiments and maturation under more typical conditions. The main results of the experiments reported here are:

- Fluid expulsion can occur in different sequences when the temperature increases in steps. This phenomenon was investigated by increasing the heating temperature and observing expulsion events. Fluid expulsion commences abruptly, and this suggests that fluid accumulates in the shale until the pressure and volume of fluid becomes large enough to drive fracturing and concomitant fluid expulsion. Some expulsion occurred later in the process when the sample was held at a constant temperature, and this can be attributed to late kerogen maturation (production of low molecular mass gaseous hydrocarbons from mature, high carbon content, kerogen). 
- It has been assumed that after nucleation, microfractures propagate more-or-less along the lamination plane and that naturally present vertical fractures connect them [48, 49]. In our experiments we observed that most of the microfractures that formed as a result of thermal decomposition of kerogen were parallel to the plane of the lamination (parallel to the bedding plane), but some of the microfractures that deviated from the planes of the lamination were oriented more-or-less perpendicular to them.

- The burst amplitude frequencies (burst amplitude probability distribution) could be represented quite well by a power law over a significant range of burst amplitudes.

- The frequency of waiting times among pressure bursts decreased monotonically with increasing waiting time.

- Pressure time-series displayed a persistent behavior to which both the pressure pulse sizes and the time intervals contributed. catagenesis during which fluid expulsion takes place at high rates, b) second stage catagenesis during which the fluid expulsion rate remains high and the simultaneous opening and closing of fractures plays an important role (in the analog experiments of Kobchenko et al. [45], the opening and closing of neighboring fractured was found to be correlated), c) third stage during which fluid is expelled at a slower but more-or-less constant rate via smaller pulses controlled by the opening and closing of fractures, and d) production of fluid at a declining rate from highly carbonaceous, high maturity, residual kerogen that is no longer capable of generating large quantities of fluid.

\section{REFERENCE}

6751 Boyer, C., Kieschnick, J., Suarez-Rivera, R., Lewis, R.E. and Waters, G., 2006. Producing gas from 676 its source. Oilfield Review, 18(3), pp.36-49.

6772 Hunt, M.J., 1979. Petroleum geochemistry and geology. WH Freeman and company.

6783 Tissot, B.P., Pelet, R. and Ungerer, P.H., 1987. Thermal history of sedimentary basins, maturation 679 indices, and kinetics of oil and gas generation. AAPG bulletin, 71(12), pp.1445-1466. 
4 Luo, X. and Vasseur, G., 1996. Geopressuring mechanism of organic matter cracking: numerical

681

682

683

684

685

686

687

688

689

690

691

692

693

694

695

696

697

698

699

700

701

702

703

704 modeling. AAPG bulletin, 80(6), pp.856-873.

5 Berg, R.R. and Gangi, A.F., 1999. Primary migration by oil-generation microfracturing in lowpermeability source rocks: application to the Austin Chalk, Texas. AAPG bulletin, 83(5), pp.727756.

6 Hantschel, T. and Kauerauf, A.I., 2009. Fundamentals of basin and petroleum systems modeling. Springer Science \& Business Media.

7 Fan, Z.Q., Jin, Z.H. and Johnson, S.E., 2012. Modelling petroleum migration through microcrack propagation in transversely isotropic source rocks. Geophysical Journal International, 190(1), pp.179-187.

8 Shuangfang, L., Huang, W., Fangwen, C., Jijun, L., Min, W., Haitao, X., Weiming, W. and Xiyuan, C., 2012. Classification and evaluation criteria of shale oil and gas resources: Discussion and application. Petroleum exploration and development, 39(2), pp.268-276.

9 Cordell, R.J., 1972. Depths of oil origin and primary migration: a review and critique. AAPG Bulletin, 56(10), pp.2029-2067.

10 Philippi, G.T., 1974. Depth of oil origin and primary migration: a review and critique: discussion. AAPG Bulletin, 58(1), pp.149-150.

11 Momper, J.A., 1978. Oil migration limitations suggested by geological and geochemical considerations.

12 Comer, J.B. and Hinch, H.H., 1987. Recognizing and quantifying expulsion of oil from the Woodford Formation and age-equivalent rocks in Oklahoma and Arkansas. AAPG Bulletin, 71(7), pp.844-858.

13 Marquez, X.M. and Mountjoy, E.W., 1996. Microfractures due to overpressures caused by thermal cracking in well-sealed Upper Devonian reservoirs, deep Alberta Basin. AAPG bulletin, 80(4), pp.570-588.

14 Kalani, M., Jahren, J., Mondol, N.H. and Faleide, J.I., 2015. Petrophysical implications of source rock microfracturing. International Journal of Coal Geology, 143, pp.43-67. 
15 Vernik, L., 1994. Hydrocarbon-generation-induced microcracking of source rocks. Geophysics, 59(4), pp.555-563.

16 Kobchenko, M., Panahi, H., Renard, F., Dysthe, D.K., Malthe-Sørenssen, A., Mazzini, A., Scheibert, J., Jamtveit, B. and Meakin, P., 2011. 4D imaging of fracturing in organic-rich shales during heating. Journal of Geophysical Research: Solid Earth, 116(B12).

17 Lash, G.G. and Engelder, T., 2005. An analysis of horizontal microcracking during catagenesis: Example from the Catskill delta complex. AAPG bulletin, 89(11), pp.1433-1449.

18 Capuano, R.M., 1993. Evidence of fluid flow in microfractures in geopressured shales. AAPG Bulletin, 77(8), pp.1303-1314.

19 Fan, Z.Q., Jin, Z.H. and Johnson, S.E., 2012. Gas-driven subcritical crack propagation during the conversion of oil to gas. Petroleum Geoscience, 18(2), pp.191-199.

20 Özkaya, I., 1988. A simple analysis of oil-induced fracturing in sedimentary rocks. Marine and Petroleum Geology, 5(3), pp.293-297.

21 Durand, B., 1988. Understanding of HC migration in sedimentary basins (present state of knowledge). Organic Geochemistry, 13(1-3), pp.445-459.

22 Hunt, J.M., 1990. Generation and migration of petroleum from abnormally pressured fluid compartments (1). AAPG bulletin, 74(1), pp.1-12.

23 Jin, Z.H., Johnson, S.E. and Fan, Z.Q., 2010. Subcritical propagation and coalescence of oil-filled cracks: Getting the oil out of low-permeability source rocks. Geophysical Research Letters, 37(1).

24 Swarbrick, R.E., Osborne, M.J. and Yardley, G.S., 2001. AAPG Memoir 76, Chapter 1: Comparision of Overpressure Magnitude Resulting from the Main Generating Mechanisms.

25 English, J.M., 2012. Thermomechanical origin of regional fracture systems. AAPG bulletin, 96(9), pp.1597-1625.

26 Bradshaw, G.A. and Zoback, M.D., 1988. Listric normal faulting, stress refraction, and the state of stress in the Gulf Coast basin. Geology, 16(3), pp.271-274.

27 Rice, J.R., 1992. Fault stress states, pore pressure distributions, and the weakness of the San Andreas fault. International Geophysics, 51, pp.475-503. 
28 Teixeira, M.G., Donzé, F., Renard, F., Panahi, H., Papachristos, E. and Scholtès, L., 2017. Microfracturing during primary migration in shales. Tectonophysics, 694, pp.268-279.

29 Kobchenko, M., Hafver, A., Dysthe, D.K. and Renard, F., 2013, April. Temporal evolution of a drainage fracture network into an elastic medium with internal fluid generation. In EGU General Assembly Conference Abstracts (Vol. 15, p. 12880).

30 Feng, J., 2011. Source rock characterization of the Green River oil shale, Piceance Creek Basin, Colorado (Doctoral dissertation, Colorado School of Mines).

31 Yildirim, L.T.O., 2014. Evaluation of Petrophysical Properties of Gas Shale and Their Change Due to Interaction with Water (Doctoral dissertation, The Pennsylvania State University).

32 Sellnau, M.C., Matekunas, F.A., Battiston, P.A., Chang, C.F. and Lancaster, D.R., 2000. Cylinderpressure-based engine control using pressure-ratio-management and low-cost non-intrusive cylinder pressure sensors (No. 2000-01-0932). SAE Technical paper.

33 Clauset, A., Shalizi, C.R. and Newman, M.E., 2009. Power-law distributions in empirical data. SIAM review, 51(4), pp.661-703.

34 Mandelbrot, B.B., 1982. The fractal geometry of nature. San Francisco, CA.

35 Feder, J., 2013. Fractals. Springer Science \& Business Media.

36 Di Matteo, T., 2007. Multi-scaling in finance. Quantitative finance, 7(1), pp.21-36.

37 Panahi, H., Kobchenko, M., Renard, F., Mazzini, A., Scheibert, J., Dysthe, D.K., Jamtveit, B., Malthe-Sørenssen, A. and Meakin, P., 2014. A 4D synchrotron X-ray tomography study of the formation of hydrocarbon migration pathways in heated organic-rich shale. arXiv preprint arXiv:1401.2448.

38 Saif, T., Lin, Q., Singh, K., Bijeljic, B. and Blunt, M.J., 2016. Dynamic imaging of oil shale pyrolysis using synchrotron X-ray microtomography. Geophysical Research Letters, 43(13), pp.6799-6807.

39 Saif, T., Lin, Q., Bijeljic, B. and Blunt, M.J., 2017. Microstructural imaging and characterization of oil shale before and after pyrolysis. Fuel, 197, pp.562-574.

40 Figueroa Pilz, F., Dowey, P.J., Fauchille, A.L., Courtois, L., Bay, B., Ma, L., Taylor, K.G., Mecklenburgh, J. and Lee, P.D., 2017. Synchrotron tomographic quantification of strain and fracture 
during simulated thermal maturation of an organic-rich shale, UK Kimmeridge Clay. Journal of Geophysical Research: Solid Earth, 122, pp. 2553-2564.

764

765

766

767

41 Ortega, O. and Marrett, R., 2000. Prediction of macrofracture properties using microfracture information, Mesaverde Group sandstones, San Juan basin, New Mexico. Journal of Structural Geology, 22(5), pp.571-588.

42 Noiriel, C., Renard, F., Doan, M.L. and Gratier, J.P., 2010. Intense fracturing and fracture sealing induced by mineral growth in porous rocks. Chemical Geology, 269(3), pp.197-209.

43 Willis, R., Fontaine, J., Paugh, L. and Griffin, L., 2005. Hydraulic Fracture Imaging.

44 Hettinger, R.D. and Roberts, L.N., 2005. Lewis total petroleum system of the southwestern Wyoming province. Wyoming, Colorado, and Utah: Petroleum Systems and Geologic Assessment of Oil and Gas in the Southwestern Wyoming Province, Wyoming, Colorado, and Utah.

45 Kobchenko, M., Hafver, A., Jettestuen, E., Renard, F., Galland, O., Jamtveit, B., Meakin, P. and Dysthe, D.K., 2014. Evolution of a fracture network in an elastic medium with internal fluid generation and expulsion. Physical Review E, 90(5), p.052801.

46 Weron, R., 2002. Estimating long-range dependence: finite sample properties and confidence intervals. Physica A: Statistical Mechanics and its Applications, 312(1), pp.285-299.

47 Bons, P.D. and van Milligen, B.P., 2001. New experiment to model self-organized critical transport and accumulation of melt and hydrocarbons from their source rocks. Geology, 29(10), pp.919-922.

48 Olsson, W.A., 1980, January. Stress-relaxation in oil shale. In The 21st US Symposium on Rock Mechanics (USRMS). American Rock Mechanics Association.

49 Smith, J.W. and Chong, K.P., 1984. Introduction to mechanics of oil shale. Mechanics of Oil Shale. Elsevier, pp.1-41. 
FIGURES AND FIGURE CAPTIONS

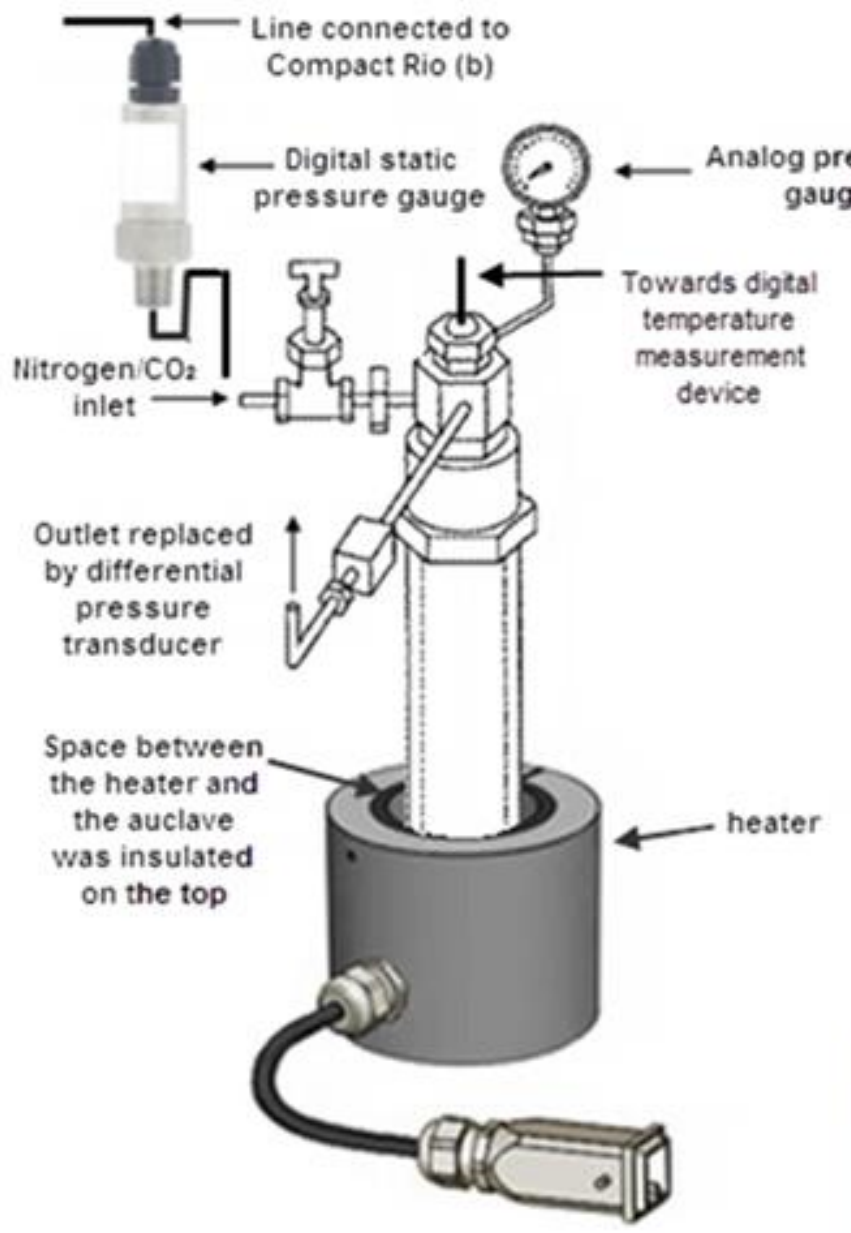

a
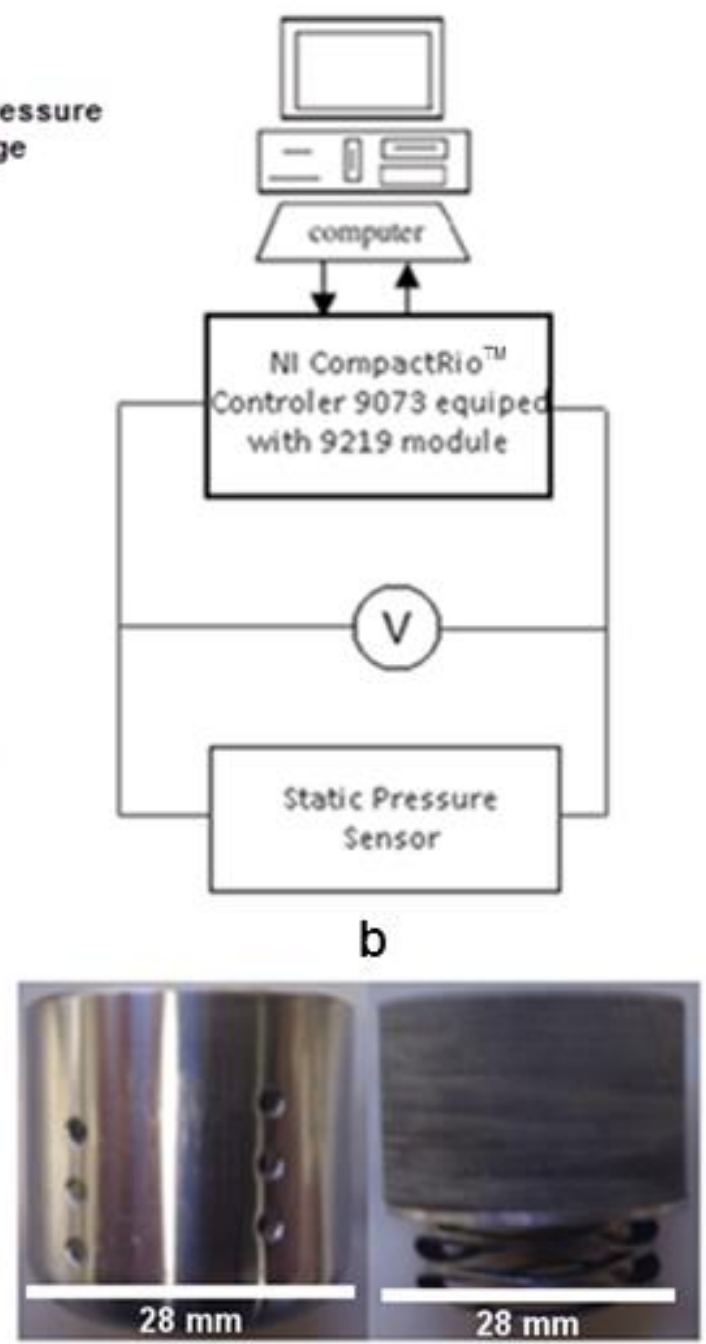

C

788 Figure 1: Experimental setup which consists of an autoclave, a Thermo Scientific Multi-Blok ${ }^{\mathrm{TM}}$ heater (one block is shown in the figure), a temperature sensor, two static pressure sensors (analog and digital), a differential pressure piezoelectric sensor, and a charge amplifier all connected to a computer via a micro controller device. a) Autoclave with sample inside the thermally insulated heating device to minimize the transport of heat from the heater to the autoclave, which is connected to a $\mathrm{CO}_{2}$ or $\mathrm{N}_{2}$ gas cylinder and pressure measuring devices; b) Static pressure sensor connected to a 20-volt power supply and LabView ${ }^{\circledR}$ software through a micro controller; c) Left: steel sample holder that houses smalldiameter samples $(25 \mathrm{~mm})$, Right: large sample $(28 \mathrm{~mm})$ on top of a reinforced wave spring. 


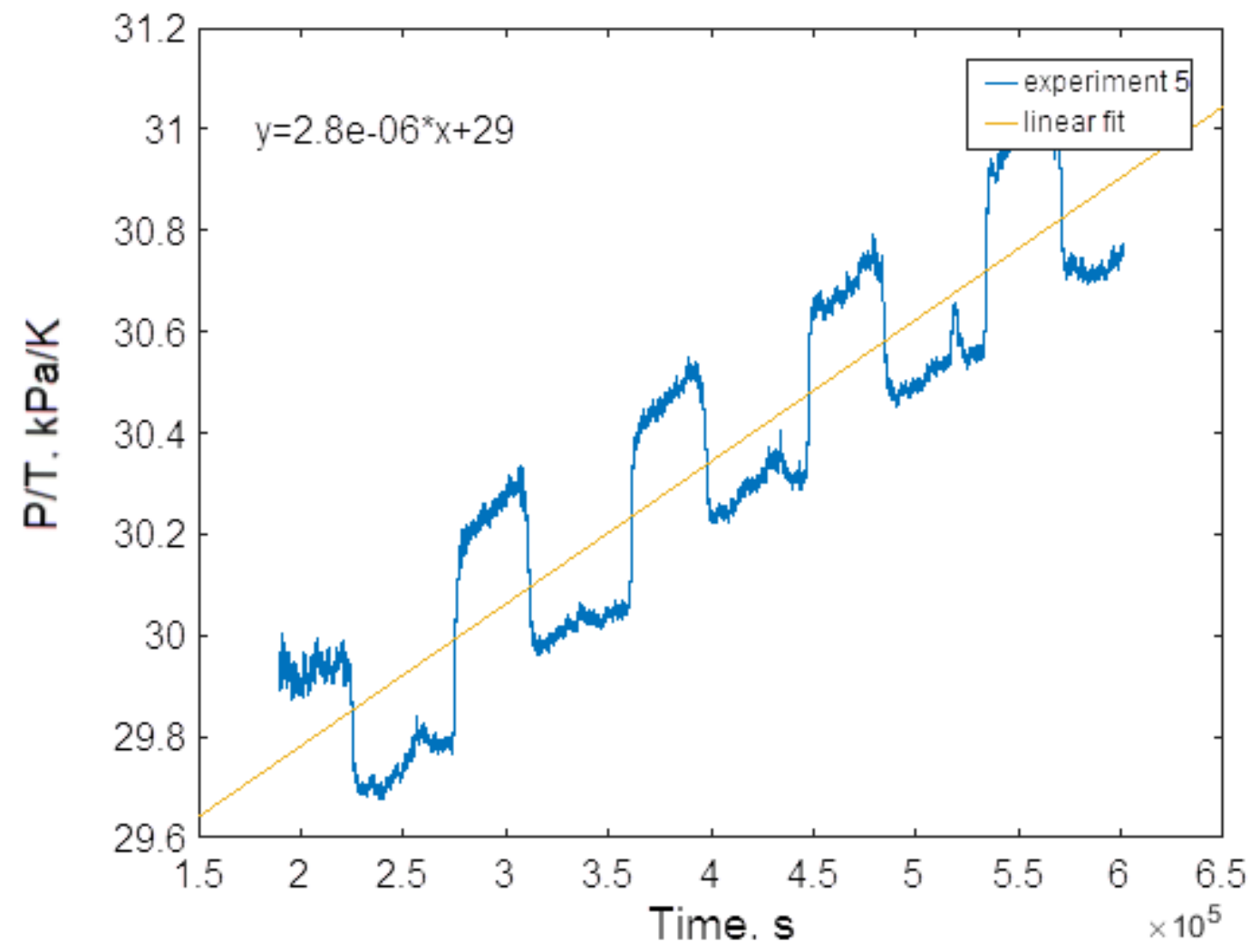

798 Figure 2: Linear regression on the temperature-stabilized part of the P/T vs. time curve for experiment

799 5. The periodic rise and fall of the pressure is caused by the on/off cycling of the heating elements 800 controlled by a thermostat. These cycles are superimposed on a more-or-less linear increase in pressure 801 caused by the production of hydrocarbon fluids. 

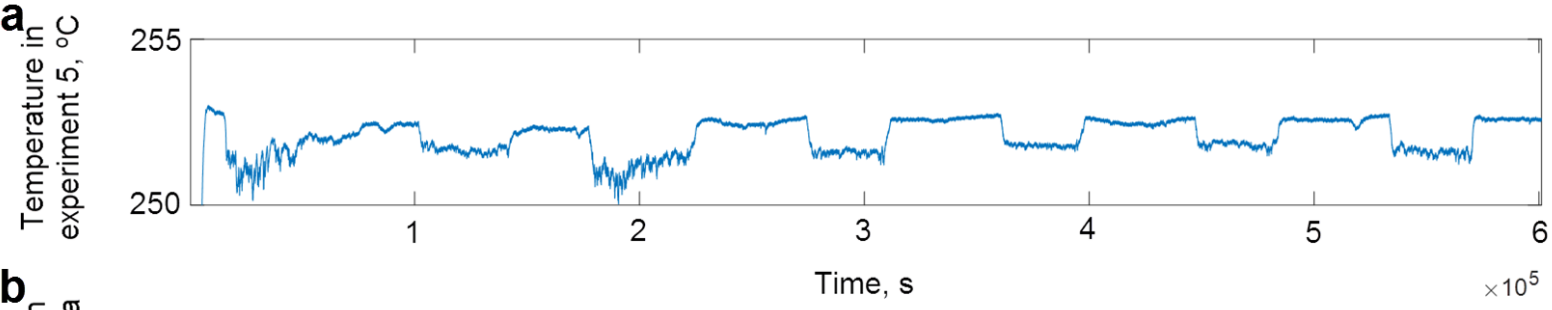

$b_{c}$

Time, s

$\times 10^{5}$

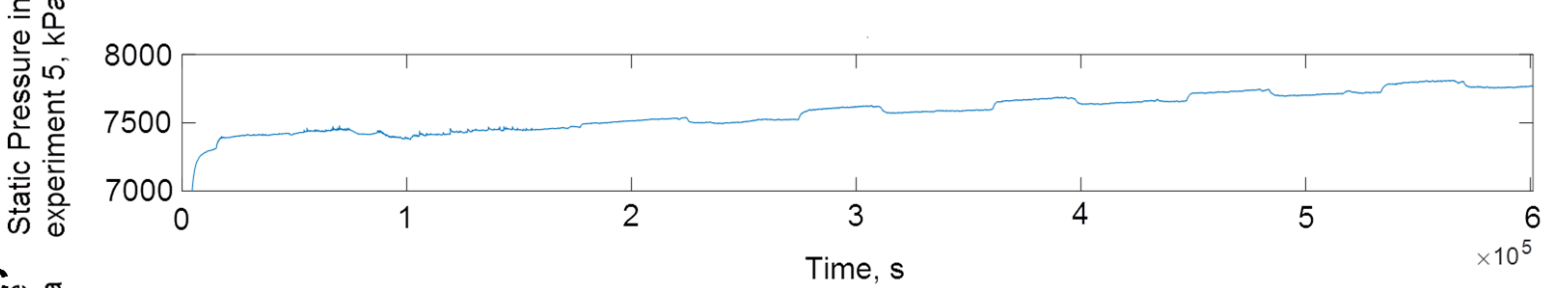

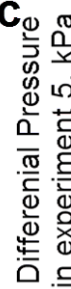

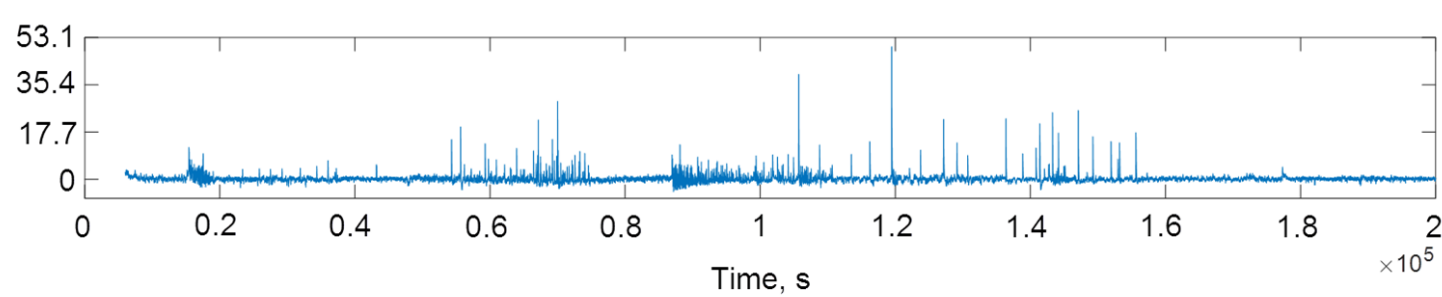

802

803 Figure 3: a) Temperature, b) Static pressure, and c) Voltage (representing differential pressure) signals

804 obtained during experiment 5. The peaks in the differential pressure signal correspond to pressure pulses related to the fluid expulsion events during kerogen during maturation. 

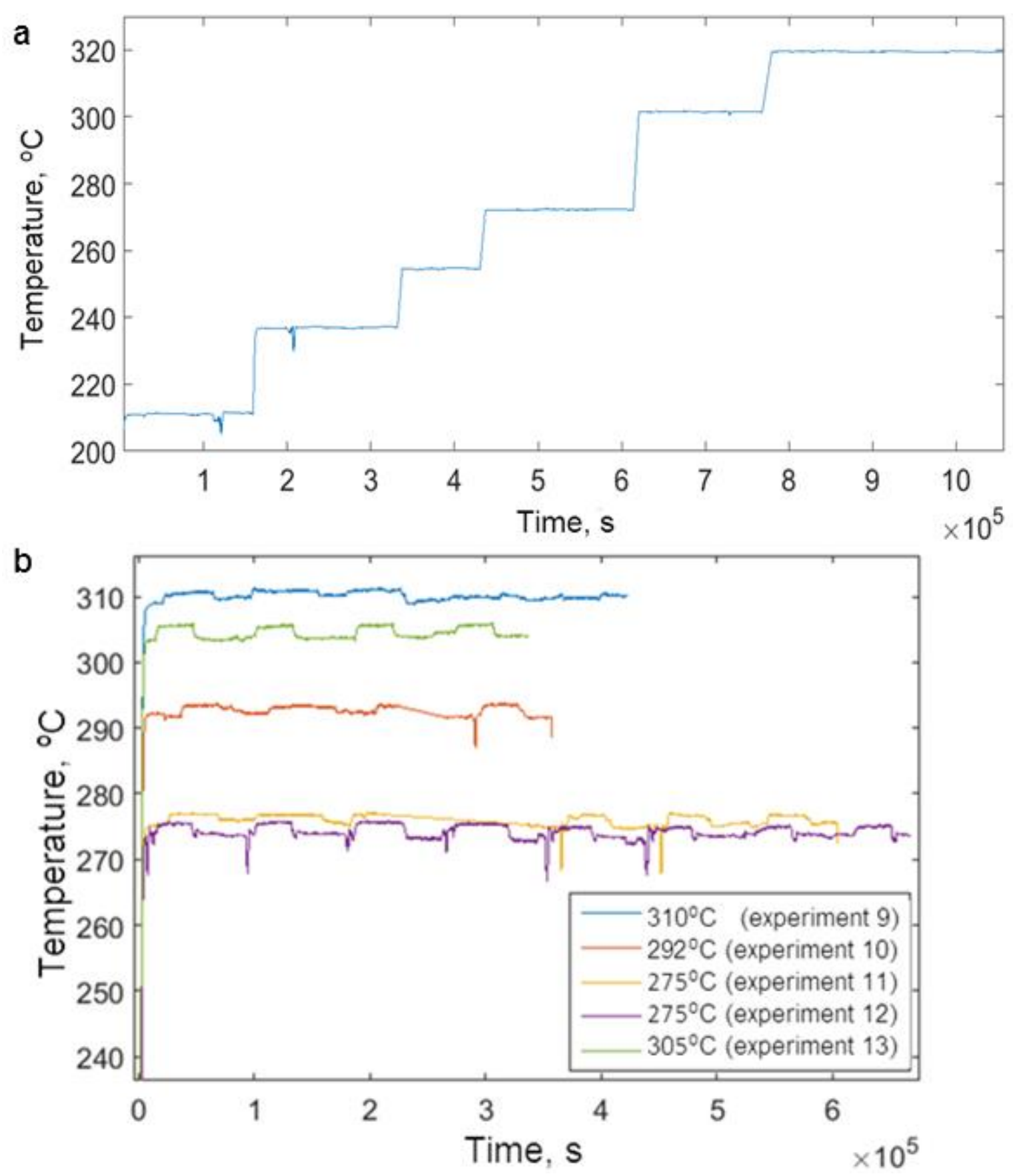

807 Figure 4: a) Temperature profile for the six stages of experiment 7, b) Temperature measured during 808 experiments $9-13$. 

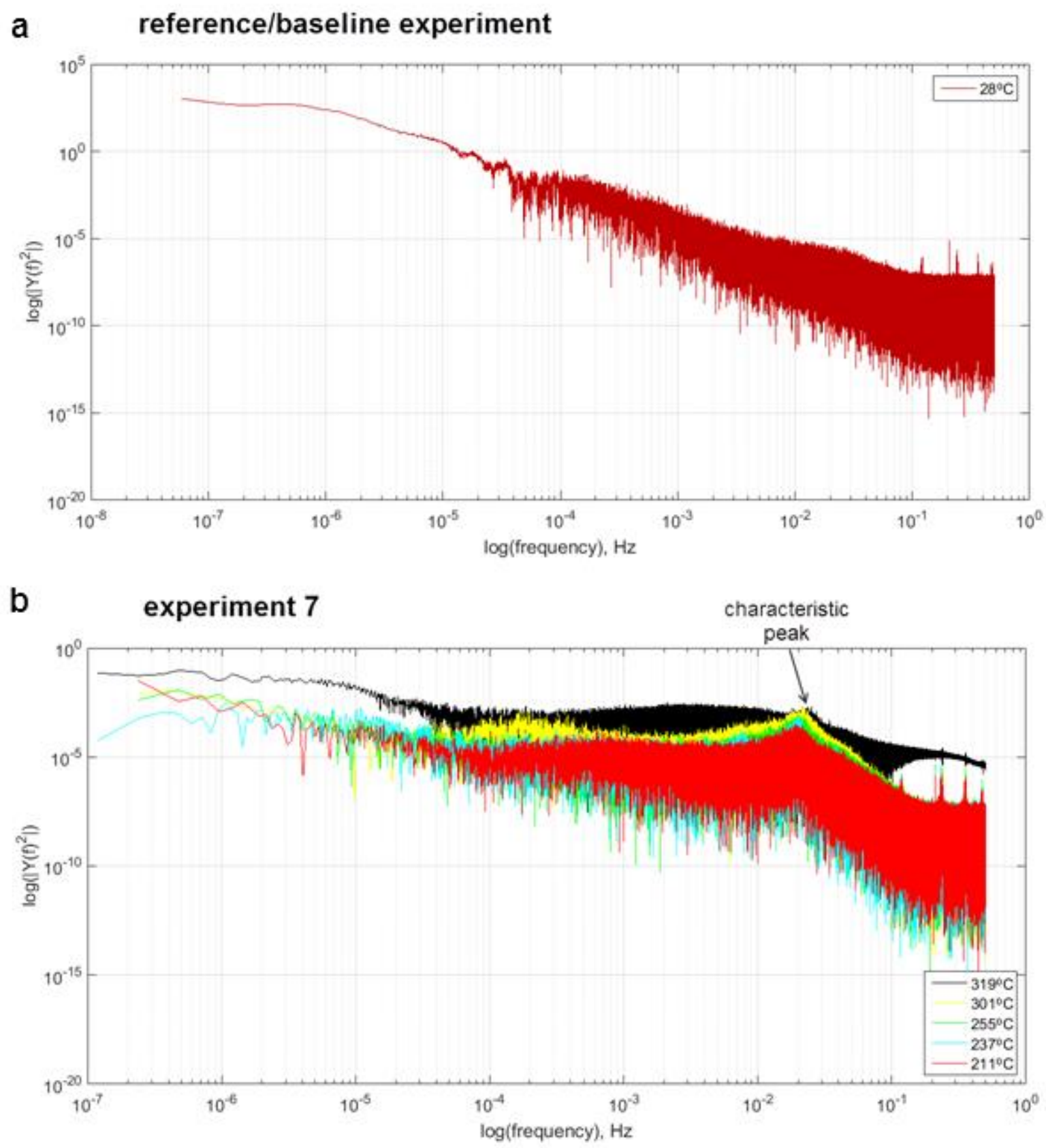

810 Figure 5: Fourier power spectra of the time series of the differential pressure sensor signal acquired in

811 experiment 7. a) Power spectrum at $28^{\circ} \mathrm{C}$ when the heater was switched off. b) Power spectra at $211^{\circ} \mathrm{C}$,

$812237^{\circ} \mathrm{C}, 255^{\circ} \mathrm{C}, 301^{\circ} \mathrm{C}$ and $319^{\circ} \mathrm{C}$ in experiment 7 on a $\log -\log$ scale showing a characteristic peak at a

813 frequency of about $2 \times 10^{-2} \mathrm{~Hz}$ (equivalent to a period of 50 seconds), which is close to the 42 second

814 relaxation time of the sensor. The low amplitude, high frequency peaks, in the upper right hand side of 815 parts a and $\mathrm{b}$, are attributed to noise in the system. 

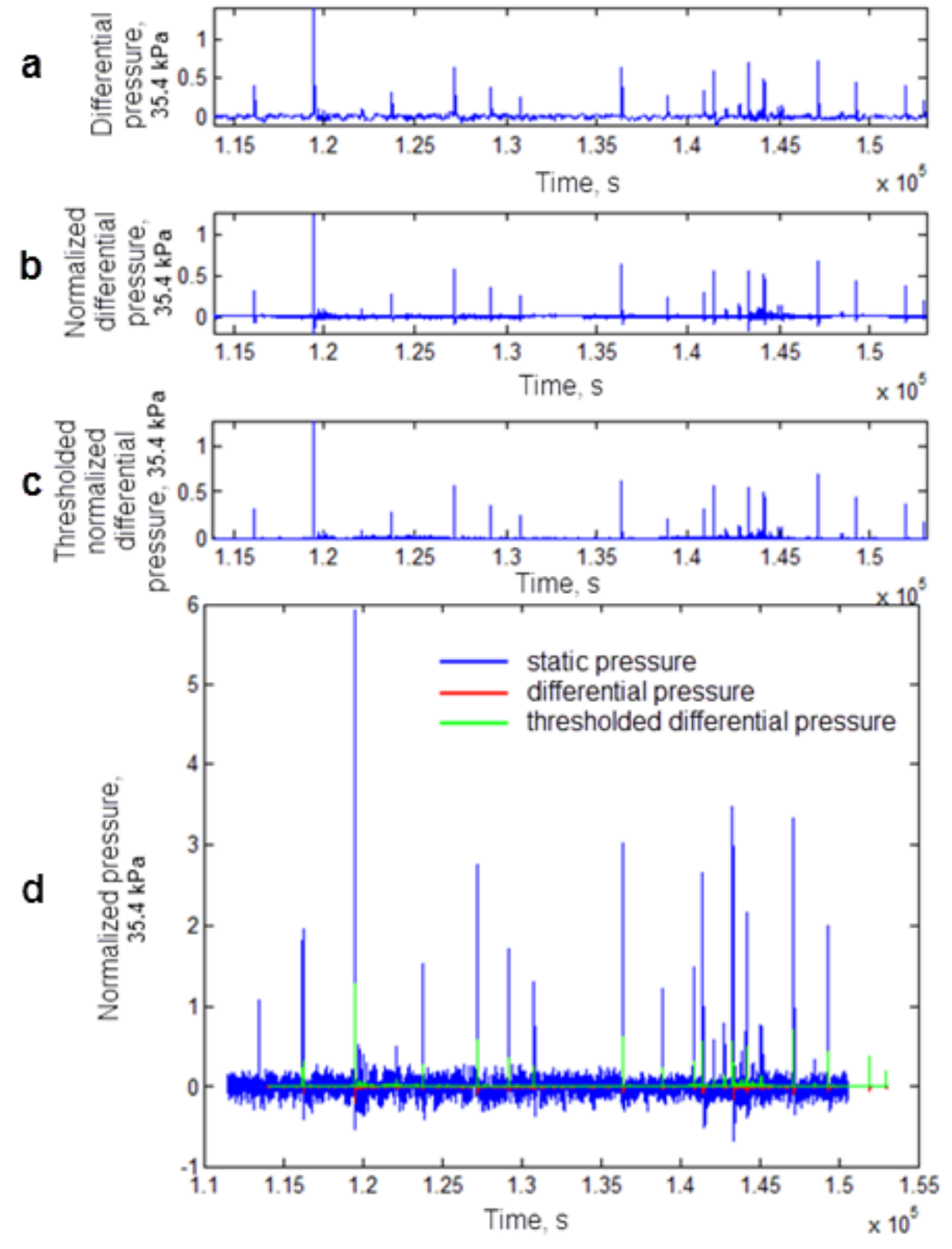

817 Figure 6: Comparison of piezoelectric transducer voltage signal representing differential pressure 818 between 107900 and 147100 seconds recorded during experiment 5 with static pressure signal. a) 819 Differential pressure within the time window; b) Differential pressure minus moving average of 820 differential pressure (normalized differential pressure); c) Differential pressure minus moving average 821 after removal of negative values; d) Comparison of the normalized static pressure (static pressure minus 822 its moving average) with normalized differential pressure and differential pressure. 


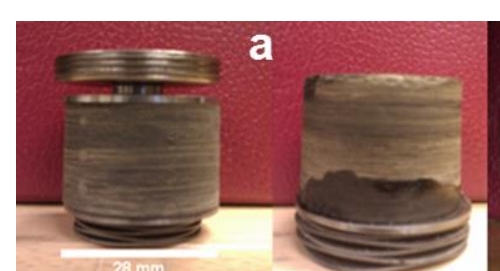

d

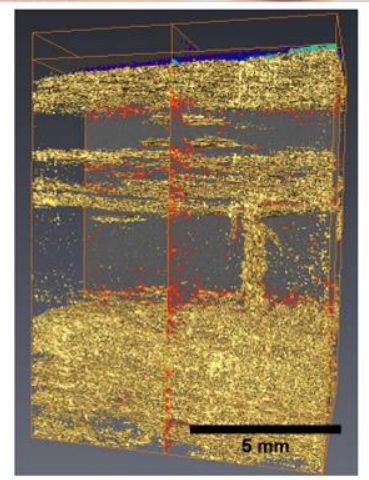

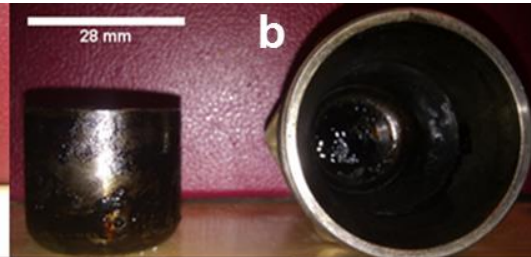

e

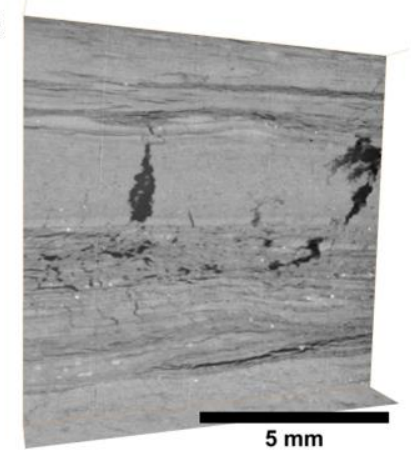

C

Small vertical cracks

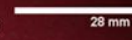
Small horizontal cracks 4) laterally

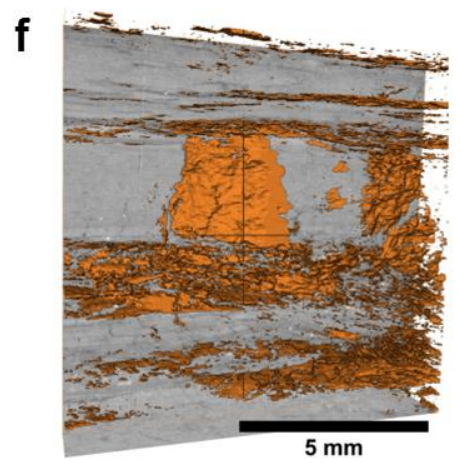

Figure 7: a) Sample before (left) and after (right) experiment 1; b) Hydrocarbon coating on the sample holder (left) and inner wall of the vessel (right) at the end of experiment 3; c) The sample after experiment 4 with both vertical and horizontal fractures; d-f) X-ray micro-tomography image of a Green

828 River Shale sample after heating at a temperature of $350^{\circ} \mathrm{C}$ for 6 days, which also shows horizontal and 829 vertical fractures. Bed-parallel and bed-perpendicular fractures were produced during the expulsion of hydrocarbon. The voxel size was 17 micrometers. The 3D rendering shows the fracture network. 

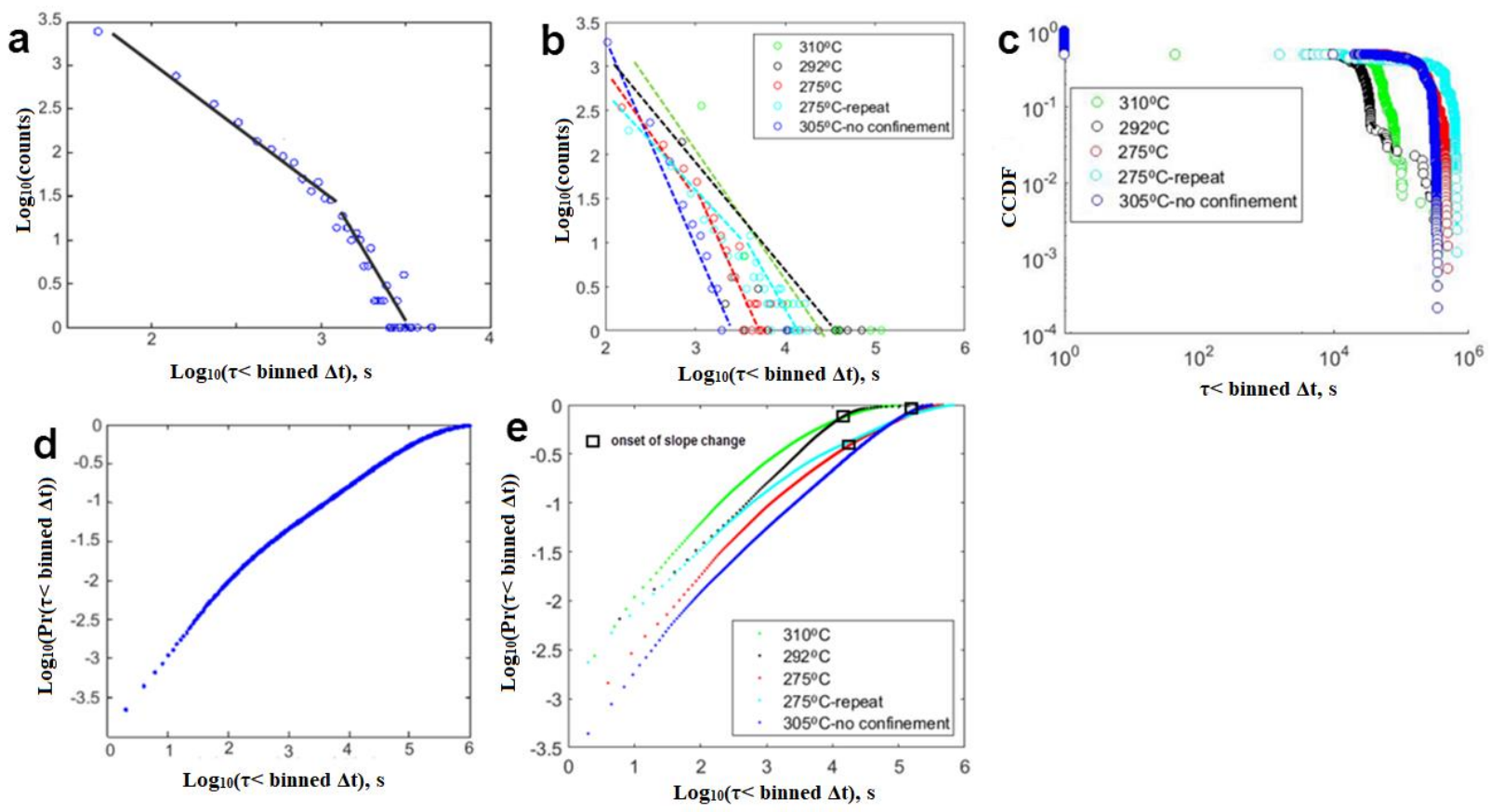

832 Figure 8: a) Probability distribution function of binned waiting times $(\Delta t)$ between pressure bursts above

833 the delay time of the sensor $(\tau)$ obtained by analyzing data from Experiment 5. b) Probability distribution

834 function for binned waiting times for experiments 9-13. The data displayed in parts a and b indicate that

835 the frequency of waiting times decreases monotonically with increasing waiting time. c) Waiting time 836 complementary cumulative probability distribution function (CCDF) for experiments 9-13. d)

837 Cumulative probability distribution of the pressure pulse waiting times for experiment 5. e) Cumulative 838 probability of the pressure pulse waiting times for experiments 9-13. 

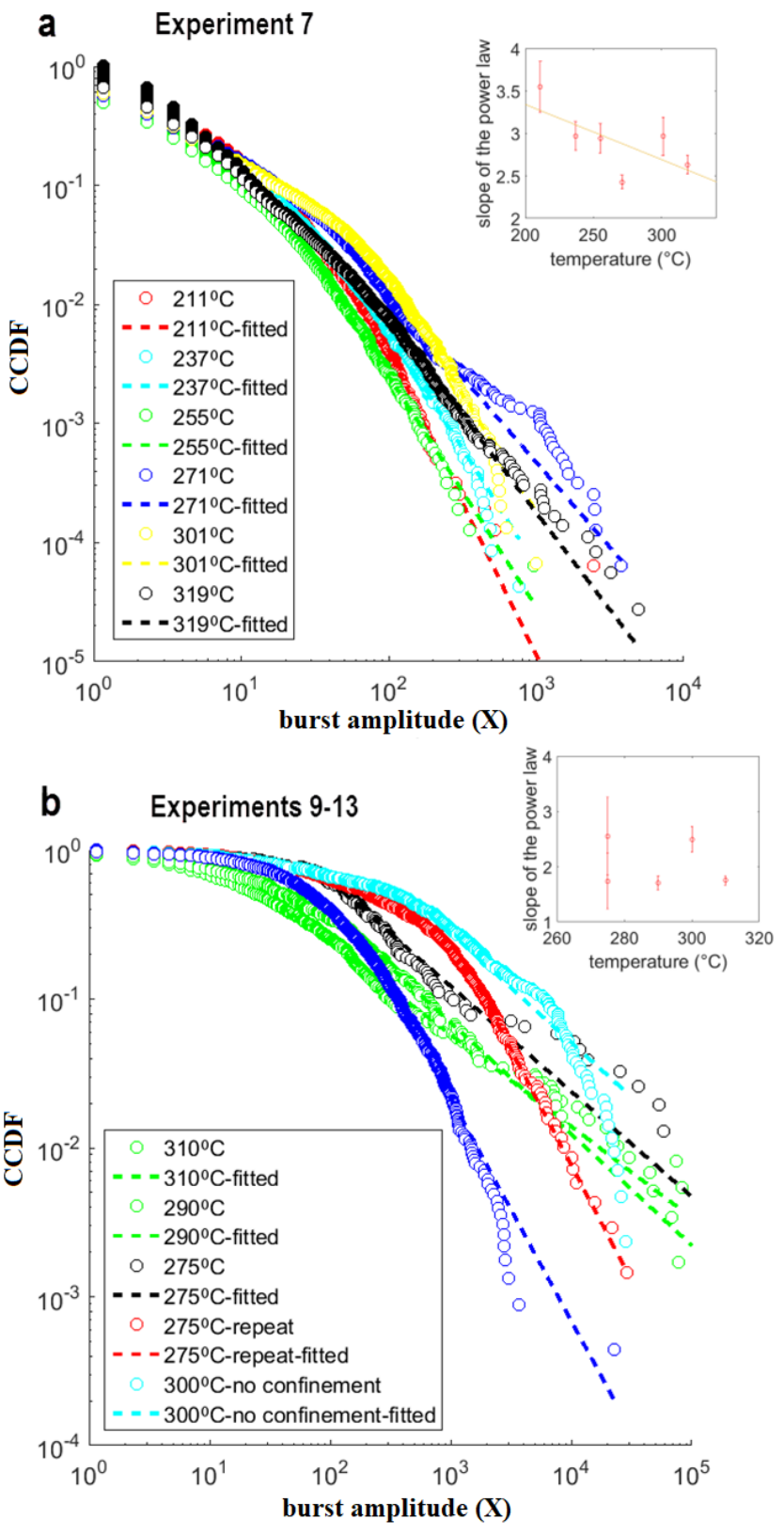

840 Figure 9: a) Complementary cumulative probability distribution function (CCDF) of pressure burst

841 amplitudes, $\mathrm{X}$, for the six temperatures of experiment 7 each represented by different colors. For large

842 burst amplitudes, the data suggest a power law distribution, and a goodness-of-fit method was used to

843 determine the power law exponent, the range of power law scaling, the lower limit of the fit (Xmin),

844 and confirm power law behavior. The power law exponent decreases as the temperature increases. b)

845 Pressure burst amplitude complementary cumulative probability distribution for experiments 9-13. Each

846 of these experiments was conducted at a constant temperature, and the effective power law exponent

847 does not change systematically as the temperature increases. 

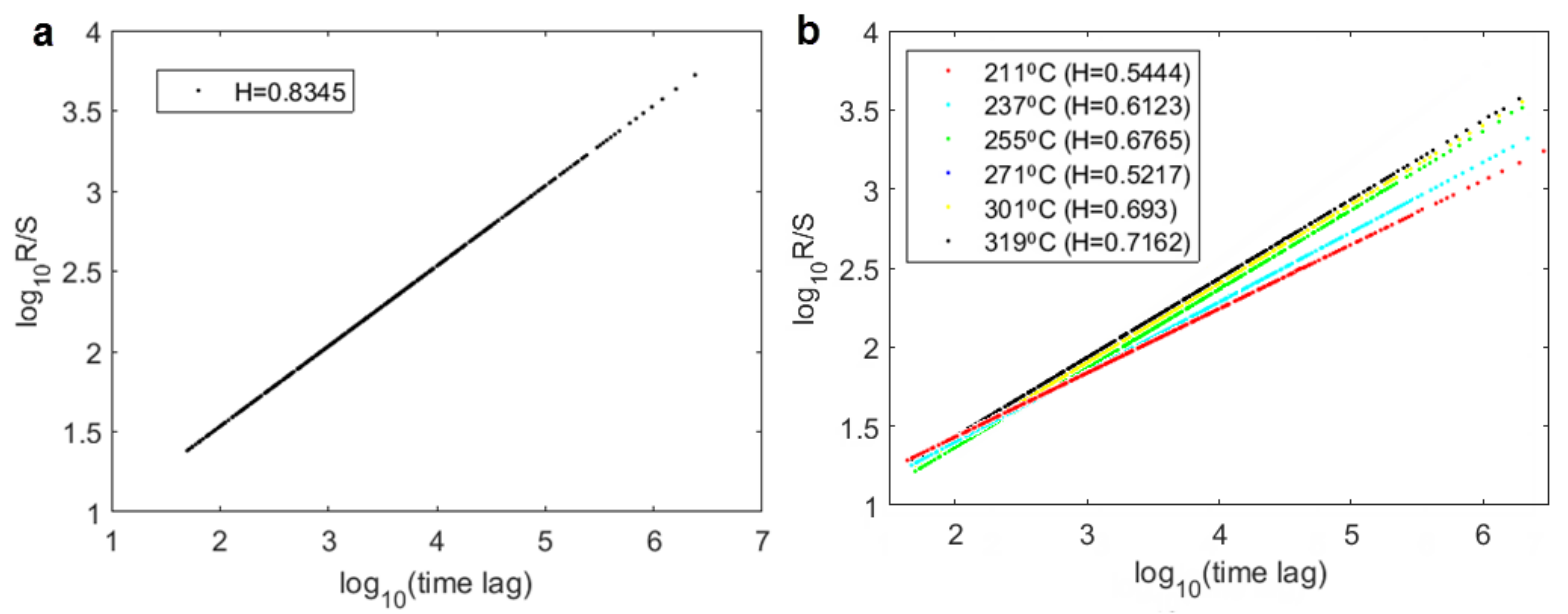

Figure 10: long term memory and self-affinity analysis for the differential pressure in experiment 5: (a),

850 all six temperatures of experiment 7 (b) showing rescaled range (R/S) versus $\Delta t$, where $\Delta t$ is the length

851 of the time interval in which R and S were measured. The method proposed in Di Matteo [2007] was

852 used to calculate the Hurst scaling exponent. Strong pressure pulse size persistence was observed in both

853 experiments. The calculated Hurst exponents determined for the cumulative de-trended pressure in

854 experiments 5 and 7 were greater than 0.5 , and this indicate persistent behavior. 


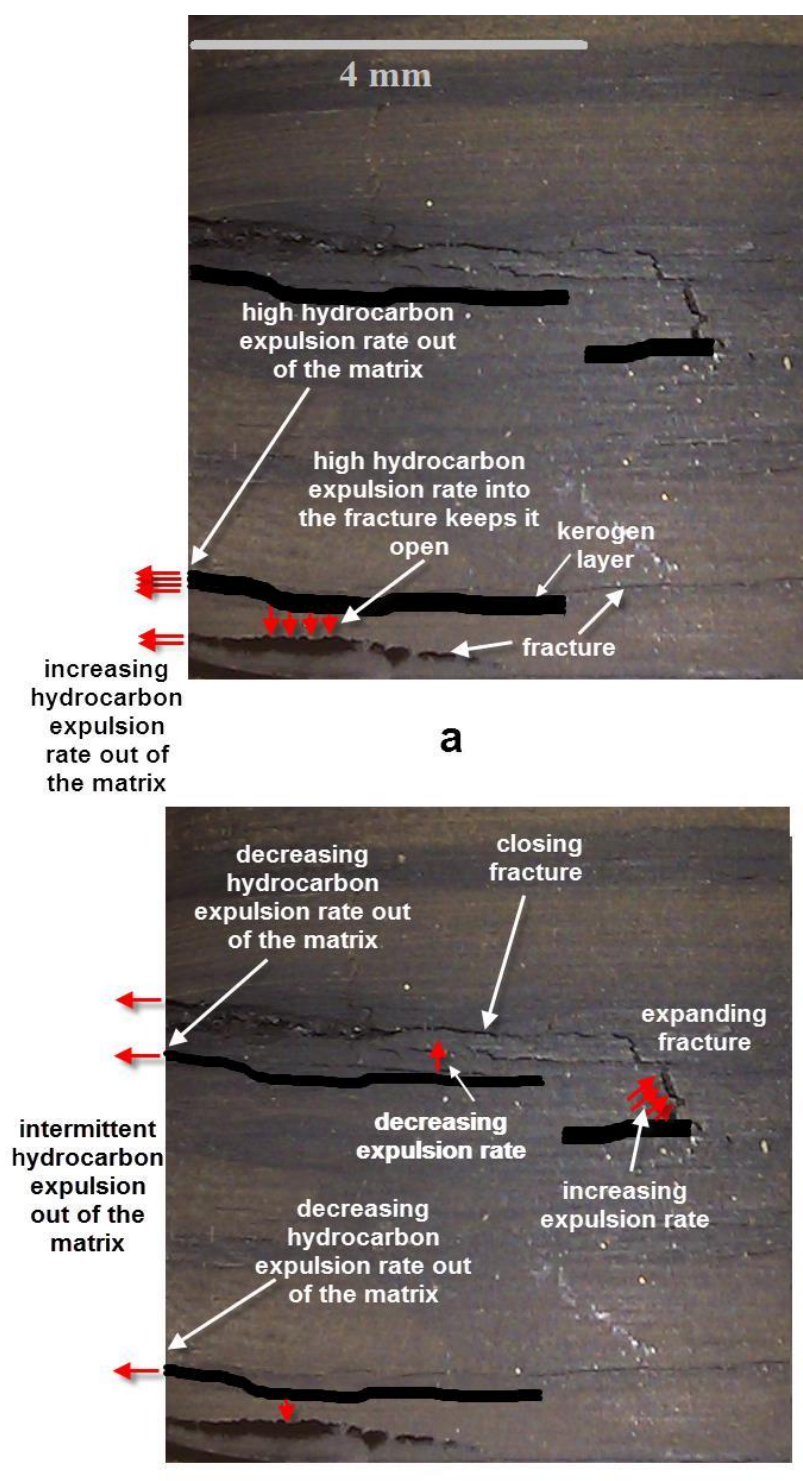

C

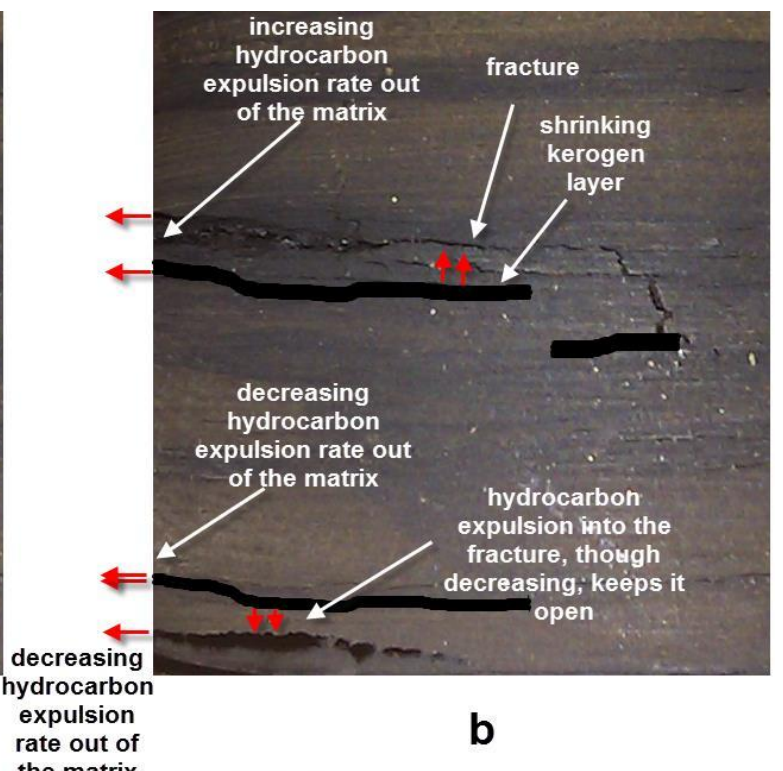

the matrix

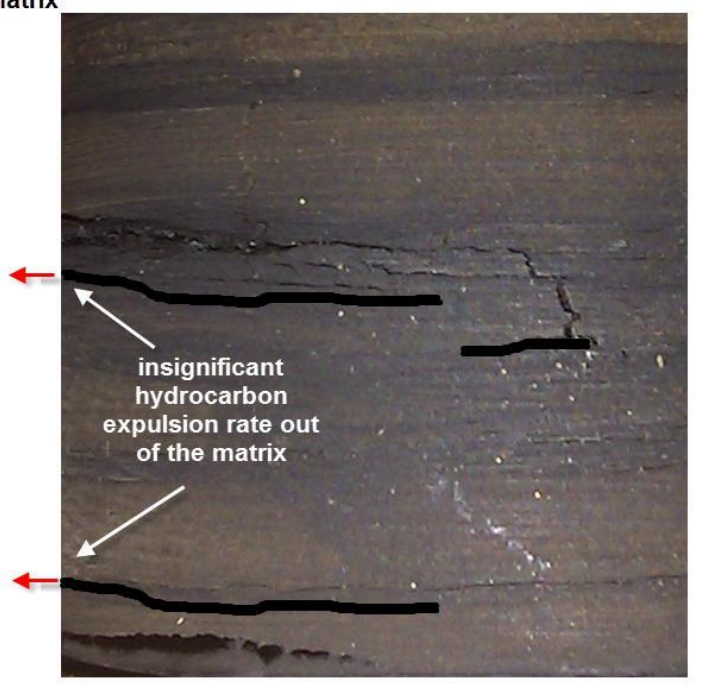

d

Figure 11: Conceptual model for various stages of gas expulsion during constant temperature experiments: Stage a) the early stage of catagenesis during which the production and expulsion of fluid takes place at high rates. Fracturing facilitates the high fluid expulsion rates. Stage b) second stage of catagenesis during which the rate of fluid expulsion remains high but decreases because the remaining, more aromatic, kerogen is more resistant to thermal generation and it has a smaller hydrocarbon production capacity. The variability in the chemical natures of different kerogen particles may contribute to maintenance of a high rate of fluid expulsion during stage $b$ because production of fluid from kerogen particles that are more resistant to thermal degradation will be prolonged. Stage c) the now more mature kerogen produces fluids at a smaller rate and the expulsion of fluids becomes intermittent. We attribute intermittent gas release to the repeated opening and closing of fractures. Stage d) the rate of fluid production declines as the $\mathrm{H} / \mathrm{C}$ and $\mathrm{O} / \mathrm{C}$ ratios become too small for fluid generation and the residual very highly mature kerogen (char) consists almost entirely of carbon. In this figure red arrows and their abundance represent hydrocarbon flux directions and magnitudes and kerogen layers thicknesses change. 
Table 1: List of experiments and experimental conditions

\begin{tabular}{|c|c|c|c|c|c|c|}
\hline Experiment number & Sample dimensions & $\begin{array}{l}\text { Experiment } \\
\text { duration }\end{array}$ & Temperature & $\begin{array}{l}\text { nitial } \\
\text { differential } \\
\text { oressure (no } \\
\text { neating) }\end{array}$ & Objective & $\begin{array}{l}\text { Total gas release after } \\
\text { temperature stabilization } \\
\frac{\text { mole }}{\text { sample volume }}\end{array}$ \\
\hline Experiment 1 & $\begin{array}{l}28 \mathrm{~mm} \text { diameter sample } \\
\text { on top of a wave spring }\end{array}$ & 2 days & $350^{\circ} \mathrm{C}$ (heater) & $\begin{array}{l}175 \mathrm{k} \mathrm{Pa} \\
\text { (wave spring) }\end{array}$ & $\begin{array}{l}\text { To study liquid } \\
\text { hydrocarbon release }\end{array}$ & N/A \\
\hline Experiment 2 & no sample & 3 days & $350^{\circ} \mathrm{C}$ (heater) & N/A & $\begin{array}{l}\text { characterize the } \\
\text { fluctuations in } \\
\text { temperature and } \\
\text { pressure when the } \\
\text { heater activated and } \\
\text { deactivated }\end{array}$ & N/A \\
\hline Experiment 3 & $\begin{array}{l}25 \mathrm{~mm} \text { diameter sample } \\
\text { inside sample holder }\end{array}$ & 4 days & $350^{\circ} \mathrm{C}$ (heater) & $\begin{array}{l}2 \mathrm{MPa} \\
\text { (holder } \\
\text { bolt) }\end{array}$ & $\begin{array}{l}\text { Conducted with shale } \\
\text { sample at a single } \\
\text { temperature }\end{array}$ & N/A \\
\hline Experiment 4 & $\begin{array}{l}28 \mathrm{~mm} \text { diameter sample } \\
\text { on top of a wave spring }\end{array}$ & 6 days & $350^{\circ} \mathrm{C}$ (heater) & $\begin{array}{l}175 \mathrm{k} \mathrm{Pa} \\
\text { (wave } \\
\text { spring) }\end{array}$ & $\begin{array}{l}\text { To study induced } \\
\text { fracture network } \\
\text { formation }\end{array}$ & N/A \\
\hline Experiment 5 & $\begin{array}{l}25 \mathrm{~mm} \text {-diameter sample } \\
\text { inside holder }\end{array}$ & 8 days & $252^{\circ} \mathrm{C}$ (autoclave) & $\begin{array}{l}2 \mathrm{MPa} \\
\text { (holder } \\
\text { bolt) }\end{array}$ & $\begin{array}{l}\text { A differential pressure } \\
\text { transducer was added } \\
\text { to the setup }\end{array}$ & $3.8 \times 10^{-5}$ \\
\hline Experiment 6 & $\begin{array}{l}28 \mathrm{~mm} \text { diameter sample } \\
\text { on top of a wave spring }\end{array}$ & 7 days & $300^{\circ} \mathrm{C}$ (autoclave) & $\begin{array}{l}175 \mathrm{k} \mathrm{Pa} \\
\text { (wave } \\
\text { spring) }\end{array}$ & $\begin{array}{l}\text { Conducted at higher } \\
\text { temperature to see if } \\
\text { larger fluid expulsions } \\
\text { could be induced }\end{array}$ & N/A \\
\hline Experiment 7 & $\begin{array}{l}25 \mathrm{~mm} \text {-diameter sample } \\
\text { inside holder }\end{array}$ & $(6 \times 2)$ days & $\begin{array}{l}211^{\circ} \mathrm{C}, 237^{\circ} \mathrm{C}, \\
255^{\circ} \mathrm{C}, 271^{\circ} \mathrm{C}, \\
301^{\circ} \mathrm{C} \text { and } 319^{\circ} \mathrm{C} \\
\text { (autoclave) }\end{array}$ & $\begin{array}{l}2 \mathrm{MPa} \\
\text { (holder } \\
\text { bolt) }\end{array}$ & $\begin{array}{l}\text { Experiment on the } \\
\text { same sample at } 6 \\
\text { different temperatures } \\
\text { consecutively }\end{array}$ & N/A \\
\hline Experiment 8 & $\begin{array}{l}25 \mathrm{~mm} \text {-diameter sample } \\
\text { inside holder }\end{array}$ & $\begin{array}{l}(7+3+1) \\
\text { days }\end{array}$ & $252^{\circ} \mathrm{C}$ and $28^{\circ} \mathrm{C}$ & $\begin{array}{l}2 \mathrm{MPa} \\
\text { (holder } \\
\text { bolt) }\end{array}$ & $\begin{array}{l}\text { Changes in voltage } \\
\text { time series with } \\
\text { acoustic emission } \\
\text { suppressed by silica } \\
\text { powder }\end{array}$ & N/A \\
\hline Experiment 9 & $\begin{array}{l}25 \mathrm{~mm} \text {-diameter sample } \\
\text { inside holder }\end{array}$ & 115 hours & $310^{\circ} \mathrm{C}$ & $\begin{array}{l}2 \mathrm{MPa} \\
\text { (holder } \\
\text { bolt) }\end{array}$ & $\begin{array}{l}\text { Similar to experiment } \\
5 \text {, but at higher } \\
\text { temperature (lower } \\
\text { data capture } \\
\text { frequency) }\end{array}$ & $9 \times 10^{-5}$ \\
\hline Experiment 10 & $\begin{array}{l}25 \mathrm{~mm} \text {-diameter sample } \\
\text { inside holder }\end{array}$ & 99 hours & $292{ }^{\circ} \mathrm{C}$ & $\begin{array}{l}2 \mathrm{MPa} \\
\text { (holder } \\
\text { bolt) }\end{array}$ & $\begin{array}{l}\text { Similar to experiment } \\
5 \text {, but at higher } \\
\text { temperature (lower } \\
\text { data capture } \\
\text { frequency) }\end{array}$ & $6.9 \times 10^{-5}$ \\
\hline
\end{tabular}




\begin{tabular}{|c|c|c|c|c|c|c|}
\hline & & & & & Similar to experiment & \\
\hline Experiment 11 & $\begin{array}{l}25 \mathrm{~mm} \text {-diameter sample } \\
\text { inside holder }\end{array}$ & 7 days & $275^{\circ} \mathrm{C}$ & $\begin{array}{l}2 \mathrm{MPa} \\
\text { (holder } \\
\text { bolt) }\end{array}$ & $\begin{array}{l}5 \text { at higher } \\
\text { temperature (with a } \\
\text { lower data capture } \\
\text { frequency) }\end{array}$ & N/A \\
\hline Experiment 12 & $\begin{array}{l}25 \mathrm{~mm} \text {-diameter sample } \\
\text { inside holder }\end{array}$ & 185 hours & $275^{\circ} \mathrm{C}$ & $\begin{array}{l}2 \mathrm{MPa} \\
\text { (holder } \\
\text { bolt) }\end{array}$ & $\begin{array}{l}\text { Similar to experiment } \\
11 \text { with a slightly } \\
\text { longer duration) }\end{array}$ & $1.2 \times 10^{-6}$ \\
\hline Experiment 13 & $25 \mathrm{~mm}$-diameter sample & 93 hours & $305^{\circ} \mathrm{C}$ & $\begin{array}{l}2 \mathrm{MPa} \\
\text { (holder } \\
\text { bolt) }\end{array}$ & $\begin{array}{l}\text { Experiment with } \\
\text { sample, but no } \\
\text { confinement }\end{array}$ & $5.8 \times 10^{-4}$ \\
\hline
\end{tabular}

872 Table 2: Burst amplitude fitting by a goodness of fit method [Clauset et al., 2009]. Xmin is minimum 873 data value (cut-off) above which the power law model is plausible.

\begin{tabular}{lcccc}
\hline Experiment 7 & $\begin{array}{c}\text { Power Law Slope } \\
\text { (absolute values) }\end{array}$ & $\begin{array}{c}\text { Standard } \\
\text { Deviation }\end{array}$ & $\begin{array}{c}\text { Power Law } \\
\text { Xmin }\end{array}$ & $\begin{array}{c}\text { No. of bursts above } \\
\text { the noise threshold }\end{array}$ \\
\hline $211^{\circ} \mathrm{C}$ step & 3.6 & 0.3 & 79.7 & 90312 \\
$237{ }^{\circ} \mathrm{C}$ step & 3.0 & 0.2 & 75.1 & 135326 \\
$255^{\circ} \mathrm{C}$ step & 2.9 & 0.2 & 34.6 & 67601 \\
$271{ }^{\circ} \mathrm{C}$ step & 2.4 & 0.1 & 42.7 & 142131 \\
$301{ }^{\circ} \mathrm{C}$ step & 3.0 & 0.2 & 99.3 & 218816 \\
$319{ }^{\circ} \mathrm{C}$ step & 2.6 & 0.1 & 95.8 & 121816 \\
& & & & \\
Experiment 9 & 1.7 & 0.1 & 135.1 & 421283 \\
Experiment 10 & 1.7 & 0.1 & 88.9 & 316344 \\
Experiment 11 & 2.5 & 0.7 & 1688.0 & 480323 \\
Experiment 12 & 1.7 & 0.5 & 627.0 & 666860 \\
Experiment 13 & 2.5 & 0.2 & 264.4 & 333804
\end{tabular}

874

875 